\title{
A Review of Pediatric Cardiovascular Risk Factors and Current Guidelines
}

\author{
Deeksha Sarma, Lawrence M. Benedict, Achintya Moulick, Randy Stevens, Vicki Mahan* \\ Department of Pediatric Cardiothoracic Surgery, Drexel University College of Medicine, St. Christopher's Hospital for Children, \\ Philadelphia, USA \\ Email: *mahan_vicki@yahoo.com
}

How to cite this paper: Sarma, D., Benedict, L.M., Moulick, A., Stevens, R. and Mahan, V. (2018) A Review of Pediatric Cardiovascular Risk Factors and Current Guidelines. World Journal of Cardiovascular Surgery, 8, 61-92.

https://doi.org/10.4236/wjcs.2018.84007

Received: March 20, 2018

Accepted: April 27, 2018

Published: April 30, 2018

Copyright $\odot 2018$ by authors and Scientific Research Publishing Inc. This work is licensed under the Creative Commons Attribution International License (CC BY 4.0).

http://creativecommons.org/licenses/by/4.0/

\begin{abstract}
Dyslipidemia is a highly prevalent condition, and includes a collection of diseases that cause increased levels of plasma triglycerides and/or cholestrol, or decreased levels of HDL-C, with a prototypical disease being familial hypercholesterolemia. Dyslipidemic conditions promote increased atherogenesis through the oxidation of lipids by macrophages, and an increased response to injury by the vascular endothelium. This vascular damage, loss of vascular compliance, and overall hardening of arteries lead to sequellae such as cardiovascular disease, cerebrovascular events, and aneurysm formation. It has been established that certain risk factors predispose individuals to the sequellae of atherosclerosis, including smoking, diabetes, hypertension, and hyperlipidemia. However, studies show that these risk factors can be seen in children as well. This review aims to assess the effect of these risk factors and demonstrate their effects through adolescence into adulthood.
\end{abstract}

\section{Keywords}

Cardiovascular Disease, Familial Hypercholesterolemia, Dyslipidemia, Atherosclerosis

\section{Introduction and Pathophysiology of Hyperlipidemia and Familial Hypercholesterolemia}

Dyslipidemia is a common condition, affecting approximately 1 in 3 individuals in the United States [1]. Dyslipidemia is a term used to describe a collection of diseases, both genetically and environmentally influenced, that cause the elevation of plasma triglycerides (TG) and/or low density lipoprotein cholesterol (LDL-C), or low levels of high density lipoprotein cholesterol (HDL-C) [2]. Though dyslipidemias are highly influenced by secondary risk factors, such as 
age, race, and lifestyle [3], genetics as a primary risk factor underlies the development of disease as well. Population meta-analyses have reported over 100 genetic loci that are associated with lipid levels. Previously unreported loci are now being added to the cohort of single nucleotide polymorphisms (SNPs) that may play a role in the genetics of dyslipidemias [4].

Because of its genetic influences, familial hypercholesterolemia $(\mathrm{FH})$ can be used as a model to understand some of the physiological derangements that contribute to dyslipidemias. Common sources of FH include defects in the low density lipoprotein receptor (LDL-R), in apolipoprotein B (ApoB), and in proprotein convertase subtilisin/kexin type 9 (PCSK9), but are certainly not limited to these genes [5]. $\mathrm{FH}$ is a prevalent form of dyslipidemia especially in younger individuals, affecting approximately 1 in 500 individuals [6] [7]. In the adolescent population, one study reported a 1 in 267 prevalence of $\mathrm{FH}$ in a community of otherwise healthy Australian adolescents [8]. The prevalence of FH can vary by ethnicity, as certain populations can harbor a greater concentration of specific genetic mutations resulting in $\mathrm{FH}$ [6]. FH is believed to have a prevalence of 1 in 217 in the United States general population (higher than the 1 in 500 statistic that was previously reported) but 1 in 211 in African Americans and 1 in 414 in Mexican Americans [9] [10].

FH is inherited codominantly, with differing phenotypes for the homozygous and heterozygous forms of the disease [6] [11]. The heterozygous form (HeFH), affecting nearly 1 in 200 worldwide, is more prevalent than the rarer and more severe homozygous form of the disorder $(\mathrm{HoFH})$, which affects approximately 1 in $1,000,000$ worldwide [12] [13]. HoFH can be distinguished from $\mathrm{HeFH}$ by either genetic characterization of mutations in the LDL-R gene, or by quantifying the activity of the LDL-R [6].

The most common cause of FH is a loss-of-function mutation in the LDL- $\mathrm{R}$ gene (of which there have been over 1700 reported), causing either reduced numbers of or decreased function in the LDL-Rs [6] [14] [15]. Other mutations include those in genes encoding the ApoB and PCSK9, both of which cause a decrease in the number of functional LDL receptors, or a decrease in the functionality of the receptors present [5]. In some cases, no causal inherited mutation was identified, but the additive effects of SNPs in the genes that influence LDL-R resulted in FH [16]. This accounts for up to $20 \%$ of FH patients [17]. In both $\mathrm{HoFH}$ and $\mathrm{HeFH}$, the levels of low density lipoprotein cholesterol (LDL-C) in the blood increase substantially over time due to insufficient clearance of LDL-C, and ultimately lead to the development of atherosclerotic fatty streaks and lesions, increasing the risk for cardiovascular disease [5] [7]. Studies report varying risk elevations of cardiovascular disease in the setting of $\mathrm{FH}$. One study reported a 3-to-13-fold increase in the risk of premature atherosclerotic cardiovascular disease compared to those individuals with normal lipid levels [13]. Another study reported a 10-to-20-fold increase of developing atherosclerotic cardiovascular disease in patients with a causal mutation [18]. Irrespective of the 
actual elevation of risk, studies clearly have shown that $\mathrm{FH}$ (and $\mathrm{HoFH}$, in particular) results in earlier and more severe structural and functional vascular deviations beginning as early as the first decade of life, including coronary artery disease and aortic valve and artery disease [6] [19]. Other manifestations of FH include cutaneous xanthomas and xanthelasmas, and corneal arcus, all of which represent cholesterol-rich depositions [20]. Studies have shown that $\mathrm{HeFH}$, when untreated, has an increased cumulative risk of a cardiovascular event by the age of 60 of at least $50 \%$ in men and approximately $30 \%$ in women [21].

The atherosclerotic outcome for $\mathrm{FH}$ patients is dependent on both age and gene-dosage, with age being a more important factor in determining atherosclerotic outcome. Despite patients receiving reductions in LDL-C of $65 \%$ from baseline levels, atherosclerotic calcification of the aorta continued, seemingly unregulated [18]. Several studies found that the progression of aortic calcification in FH patients was independent of TC, LDL-C, age of cholesterol, and the aortic calcification score [17] [18] [22]. Additionally, several studies found that cardiovascular disease was much more likely in patients with a causal mutation for FH than those without [23]. This substantiates the need for early intervention (both pharmacological and lifestyle) in those with a genetic predisposition for $\mathrm{FH}$, as the development of cardiovascular disease may be delayed [18]. Because of the global and systemic nature of $\mathrm{FH}$, this condition can be used as a prototypic model for hyperlipidemia and its sequelae, including, but not limited to myocardial infarction, coronary artery disease, aortic aneurysm formation, and cerebrovascular events.

\section{Pathophysiology of Atherosclerosis}

Atherosclerosis refers to the progressive hardening of blood vessels, beginning as early as childhood, and typically manifesting clinically during adulthood [24]. The pathogenesis of atherosclerosis is complex in nature, involving many factors such as hemodynamics, thrombosis, carbohydrate-lipid metabolics, and features inherent to the arterial endothelium [25]. Atherosclerotic vascular hardening occurs due to three fundamental processes: the accumulation and proliferation of arterial intimal smooth muscle cells and leukocytes, the formation of an enlarged tissue matrix consisting of collagen, elastin fibers, and proteoglycans, and the accumulation and deposition of lipids into the cells and surrounding connective tissue matrix [24] [26]. Atherogenesis typically occurs at sites with a disturbance in the normal laminar flow of blood, especially at vessel narrowings, bifurcations, and branch points [26].

The leading hypotheses that identify the cause of initiation of atherogenesis include the "response to injury" hypothesis, and the "oxidation" hypothesis [24] [27]. The response to injury hypothesis states that endothelial damage is an initiating factor in atherogenesis. Disruption of normal endothelial function activates vasoconstricting and proliferative agents, such as thromboxane A2, prostaglandins, intracellular $\mathrm{Ca}^{2+}$, and endothelin-derived factors. Platelet adherence 
and aggregation along with intimal leukocytic infiltration cause progressive herniation and narrowing of the vessel lumen, increasing potential for vascular damage, cellular injury, and oxidative stress [24]. Both the innate and adaptive limbs of the immune response have been implicated in atherosclerosis, with cytokines and chemokines being chief directors of leukocytic and other immune cell migration into and proliferation within the intimal layer [28].

The oxidation hypothesis states that the oxidation of lipids is an inciting factor in the development of atherosclerotic lesions. Due to elevated serum lipids, lipids and lipoproteins deposit in the vessel walls and are phagocytosed by macrophages. The macrophages initiate lipid peroxidation in an attempt to destroy the lipid deposits and release the fatty acids. This causes a release of reactive oxygen species (ROS). However, ROS is toxic to plasma membranes and causes a reorganization of the cell structure, especially in actin polymerization [24] [29] [30]. Additionally, these lipid-laden macrophages, termed "foam cells," can cause recruitment of more inflammatory cells, including monocytes and $\mathrm{T}$ lymphocytes, to the site of lipid deposition, leading to further cellular and vascular damage [24] [30] [31] [32].

Atherosclerotic lesions are classified based upon their histological appearanc and can be divided into two main categories [27]. Early atherosclerotic lesions, which precede and may initiate the formation of more advanced type lesions, include Types I, II, and III [27]. These early atherosclerotic lesions cannot be detected using angiography [33]. Advanced atherosclerotic lesions are associated with increased intimal disorganization, thickening, and deformation. These include Types IV, V, and VI [27]. Advanced atherosclerotic lesions can undergo complications such as thrombosis, aneurysmal dilation, fissure, and rupture [24] [26] [27].

Type I lesions are the first lesions seen on microscopy and can be frequently found in infants and children. They are characterized by minimal intimal change with isolated foam cell and macrophage accumulation. These are very similar to type II lesions, though type II lesions are more prominent and can be visualized upon gross examination as yellow-colored streaks [27]. Histologically, type II lesions, also known as "fatty streaks", contain more subintimal macrophages, T lymphocytes, and lipid-laden macrophages and smooth muscle cells [24] [27]. Much of the lipid is contained intracellularly. If type II lesions are found in specific and predictable areas of the arterial vasculature, including the bifurcations and branch points of vessels, they are referred as "progression-prone type IIa lesions". These predictable locations include the aorta (commonly distal to the ascending aorta) and coronary arteries. Type III lesions are considered the transition between type II lesions and atheromas (type IV). They are characterized by an increased amount of extracellular lipid deposition that disrupts the normal cohesive nature of the vascular smooth muscle cells [27].

Type IV lesions, or atheromas, are histologically characterized by a well-defined core of extracellular lipid accumulation. This lipid core causes severe intimal 
disorganization and arterial wall thickening. There is a more concentrated density of macrophages, foam cells, and lymphocytes in the periphery of the lesion. When there is an increase in the fibrous tissue within and surrounding the lesion, this indicates the progression to a type $\mathrm{V}$ lesion. Also called a fibroatheroma, the type Va lesion is characterized by a fibrous cap in and around the lipid core. Type $\mathrm{Vb}$ lesions are characterized by calcification of the lipid core, while type Vc lesions are characterized by an absent lipid core. Type V lesions are clinically relevant and potentially dangerous, as they have the potential to develop fissures, hematomas, and thrombi. Type VI lesions, also termed "complicated lesions", are those that are characterized by increased disruption of the surface of the lesion, hematoma/hemorrhage, and deposition of thrombi; this type of lesion (and its associated atherosclerotic events) is what causes the most morbidity and mortality associated with atherosclerosis [33].

Visible signs of cholesterol deposition include tendon xanthomata, cutaneous xanthelasmas, or corneal arcus. These can accompany the clinical manifestations of atherosclerotic disease, which present during adulthood, and are more associated with the advanced type lesions [6] [33]. These manifestations include unstable or acute angina and ischemia, chronic stable angina and incomplete occlusion of vessels, cerebrovascular events, and aortic and peripheral artery obstructions [33]. It has been shown that the presence of atherosclerotic disease in one arterial bed is positively associated with concurrent involvement of other vessels [34]. These clinical manifestations can be used as markers to understand the progression of atherosclerosis as related to various risk factors for atherogenic development.

\section{Risk Factors}

Risk factors for atherosclerosis in adults consist of those that are modifiable and those that are not modifiable. Modifiable risk factors include smoking, obesity, physical inactivity, and certain disease states such as diabetes, hypertension, and hyperlipidemia [24] [35]. These risk factors can be corrected using lifestyle modifications and/or pharmacotherapy. Non-modifiable risk factors include age, gender, family history, genetic predispositions, forms of lipoprotein (a), and homocysteine levels [24].

The risk factors associated with adult atherosclerosis have also been implicated in children, and contribute to the earlier development of disease in children [35]. Additionally, the effects of the various risk factors are additive, with their combined effect greater than the sum of their individual effects, and their respective effects become greater as age increases [36]. Several other diseases typically diagnosed in childhood can create an additive effect with early dyslipidemia diagnoses, including type 1 diabetes mellitus, connective tissue diseases, chronic kidney disease, and HIV [37]. By understanding the risk factors seen in children that can lead to hyperlipidemia and eventual atherosclerosis, better treatment plans can be created for the future care of dyslipidemia in the pedia- 
tric population.

Studies notable in their efforts to elucidate the relationships between various risk factors of cardiovascular disease include the Muscatine and Bogalusa studies [38]. The Muscatine study, a longitudinal study conducted with over 14,000 predominantly white children aged 8 - 18 years, followed subjects every 10 years with repeated testing. Levels of carotid artery atherosclerosis were determined using noninvasive B-mode ultrasound and used as a marker of overall cardiovascular health and atherosclerosis in the body [39]. The Bogalusa study, another longitudinal study, is one of the longest and most detailed prospective studies of childhood risk factors in the study of coronary artery disease and hypertension [38]. This study consists of a population of both white and black school-aged children and young adults up to 35 years of age. The study measures multiple risk factors including BMI, triceps skinfold thickness (as a measure of obesity and body fat levels), lipid profile, and smoking status [38] [40]. Many hypotheses of risk factor associations have been corroborated between childhood and adulthood [38].

This review will assess various risk factors and associations made with manifestations of cardiovascular disease, including atherosclerosis, increased carotid intimal-medial thickness, cerebrovascular events (stroke), aortic plaques, and involvement of specific arterial vasculature.

\subsection{Smoking}

\subsubsection{Active Smoking}

Active smoking is defined as a current or past history of cigarette smoking, while passive smoking is defined as being exposed to cigarette smoke. A study examining the relationship between active smoking in male adolescents (aged 15 18 years) and dyslipidemia found that adolescents who smoked more than 5 cigarettes per day or smoked for more than 2 years increased total cholesterol (TC) and TG levels significantly, while those who smoked more than 5 cigarettes per day additionally significantly increased LDL levels [41]. Those adolescents who smoked less than two years $(n=15)$ had a mean TG difference of 49.4 points lower than those who smoked for greater than two years $(n=35 ; \mathrm{p}<0.001)$; additionally, those adolescents who smoked less than 5 cigarettes a day $(n=24)$ had a mean TG difference of 29.1 points lower than those who smoked more than 5 cigarettes a day $(n=26 ; p=0.02)$ [41]. These conclusions have been replicated in several other studies, both in pediatric and adolescent populations [42] [43].

In a study examining the presence of atherosclerotic lesions as a result of various risk factors, researchers found that there was a significantly higher prevalence of raised fatty lesions found in the abdominal aorta in white male smokers from ages 15 - 34 [36]. Smoking was also found to be a strong environmental risk factor for coronary artery disease in men with HeFH $(\mathrm{p}<0.005)$, but not in women with $\mathrm{HeFH}$ [44]. Smoking has been postulated to alter the gene expression of those genes involved in TG and LDL levels and has been categorized as a 
high-risk factor for atherosclerosis, along with high VLDL or LDL and low HDL [45] [46].

One mechanism that contributes to the vascular damage that is seen as a result of cigarette smoking is due to increased oxidant stress [47] [48]. One study found that oxidant stress, measured by levels of $\mathrm{PGF}_{2 \mathrm{a}}$, a stable product of lipid peroxidation, was increased significantly in chronic smokers with a median of 15 pack-years of smoking (mean \pm SEM, $122.5 \pm 10.8 \mathrm{pmol} / \mathrm{mmol}$ creatinine) as compared to nonsmoking control subjects $(63.7 \pm 5.0 \mathrm{pmol} / \mathrm{mmol}$ creatinine, $\mathrm{p}$ $<0.005)$ [47]. This study also found a significant dose-response relationship between the number of cigarettes smoked and urinary levels of $\mathrm{PGF}_{2 \mathrm{a}}$ (indicating increased $\mathrm{PGF}_{2 \mathrm{a}}$ production), with heavy smokers excreting more $\mathrm{PGF}_{2 \mathrm{a}}$ than moderate and matched nonsmokers $(176.5 \pm 30.6 \mathrm{pmol} / \mathrm{mmol}$ creatinine in heavy smokers; $92.7 \pm 4.8 \mathrm{pmol} / \mathrm{mmol}$ creatinine $(\mathrm{p}<0.05)$ in moderate smokers, $54.1 \pm 2.7 \mathrm{pmol} / \mathrm{mmol}$ creatinine $(\mathrm{p}<0.005)$ in nonsmokers) [47]. Furthermore, the effect of the antioxidant vitamin $\mathrm{C}$ on $\mathrm{PGF}_{2 \mathrm{a}}$ levels was shown to be significant, with a decrease by an average of $29 \%$ of urinary excretion of $\mathrm{PGF}_{2 \mathrm{a}}$ [47]. Vitamin $\mathrm{C}$ is a very potent defense against oxidant stress for plasma lipids and LDL, and has shown to be decreased in chronic smokers [49] [50] [51]. This relationship has been observed in passive smokers' exposure to secondhand smoke (SHS) as well [48] [52]. Overall, the increased oxidant stress on the body caused by cigarette smoking is deleterious to vascular health [31] [48]. Increased oxidation of LDL induces the accumulation of cholesterol in macrophages, producing "foamy macrophages" [30] [31] [32]. The oxidized LDL can then recruit more inflammatory cells, including monocytes and T lymphocytes, to the site of forming atherosclerotic lesion [31] [32] [48] [53] [54]. Overall, these studies support the strong association between active smoking and the development of atherosclerosis. A summary of study conclusions can be found in Table 1 .

\subsubsection{Passive Smoking}

Second-hand smoke has been associated with cardiovascular events and atherosclerosis in adults, but recent research has found that the effects can stem as early as in childhood and adolescence [55]. Among many others, one mechanism by which negative cardiovascular effects occur after secondhand smoke is endothelial dysfunction [56] [57] [58] [59]. Upon exposure to tobacco smoke, endothelial cells subjected to sudden increased flow do not produce as much NO, thereby causing impaired dilation of the arterial vessel [57] [60]. This dilation of the brachial artery is largely mediated by endothelium NO secretion. Decreased levels of NO production, in turn, prevent NO's normal inhibition of events implicated in the development of vascular disease, such as platelet aggregation, smooth muscle proliferation, and monocyte adhesion to cells [57] [58] [59] [60]. Most notable is the fact that this endothelial dysfunction as a result of even low levels of secondhand smoke exposure can be seen in young children of 11 years old [55] [57].

After placing Tibetan adolescent males in groups based on their levels of serum 
Table 1. Summary of conclusions for active smoking risk factor.

\begin{tabular}{|c|c|c|c|}
\hline$\underline{\text { References }}$ & Sample size & p-value & Conclusion \\
\hline \multirow{3}{*}[41]{} & 100 & & $\begin{array}{l}\text { Adolescents who smoked }>5 \text { cigarettes/day had } \\
\text { increased TC, TG, and LDL-C levels. They also } \\
\text { had decreased HDL-C levels. Adolescents who } \\
\text { smoked }>2 \text { years had increased TC and TG } \\
\text { levels. }\end{array}$ \\
\hline & 15 & $\mathrm{p}<0.001$ & $\begin{array}{l}\text { Adolescents who smoked }<2 \text { years had a mean } \\
\text { TG level } 49.4 \text { points lower than those who } \\
\text { smoked for }>2 \text { years. }\end{array}$ \\
\hline & 26 & $\mathrm{p}=0.02$ & $\begin{array}{l}\text { Adolescents who smoked }<5 \text { cigarettes/day had } \\
\text { a mean TG difference of } 29.1 \text { points lower than } \\
\text { those who smoked }>5 \text { cigarettes/day. }\end{array}$ \\
\hline [36] & & & $\begin{array}{l}\text { White male smokers from the ages } 15 \text { - } 34 \text { have } \\
\text { a significantly higher prevalence of raised fatty } \\
\text { abdominal aortic lesions than their } \\
\text { non-smoking counterparts. }\end{array}$ \\
\hline [44] & 364 & $\mathrm{p}<0.005$ & $\begin{array}{l}\text { Smoking is a positive influence on the } \\
\text { development of coronary artery disease in men } \\
\text { with } \mathrm{HeFH} \text {, but not in women with } \mathrm{HeFH} \text {. }\end{array}$ \\
\hline [47] & 24 & $\mathrm{p}<0.005$ & $\begin{array}{l}\text { Chronic smokers have dose-related increased } \\
\text { levels of products of oxidative reactions as } \\
\text { compared to their non-smoking counterparts. }\end{array}$ \\
\hline
\end{tabular}

cotinine (a chief metabolite of tobacco in cigarettes used as a marker of recent exposure (within 2 - 3 days) to secondhand smoke), it was shown that all serum levels of cotinine were associated with early markers of atherosclerosis and endothelial dysfunction [55] [57] [61]. Adolescents with high levels of serum cotinine showed more deterioration of cIMT $(\mathrm{p}<0.001)$ and intimal smoothness ( $\mathrm{p}$ $<0.05)$ as compared to those with low levels of serum cotinine; additionally, vascular endothelial function was significantly more decreased in the adolescents in the high cotinine level group, after taking measurements of flow-mediated dilation of vessels and ankle-brachial index ( $p<0.001$ for both measurements) [55]. Likewise, both past and current exposure to SHS is associated with increased intima-media thickness of the carotid artery (cIMT) [62]. The effect of passive exposure to secondhand smoke in young children and adolescents has also been found to have a dose-dependent effect on vascular function [52] [57]. The endothelium-dependent flow dilation of the brachial artery after mechanical constriction of the vessel showed a significant dose-dependent relationship between increased levels of serum cotinine and increased levels of endothelial dysfunction in children of 8 and 11 years old [57].

Cardiovascular dysfunction due to smoking (both passive and active) can also result from the increased oxidant stress that is placed on the endothelium, due to the high levels of oxidants and pro-oxidants that are found in SHS [48]. This can eventually lead to the creation of oxidized LDL resulting in the formation of foam macrophages, and is therefore a key event in the development of atheros- 
clerosis [31] [48]. A study examining the serum antioxidant defenses of adults from the ages of 23 - 39 years found that the serum antioxidant activity was significantly decreased after subjects were exposed to passive smoke for 30 minutes [48]. This short exposure to SHS caused a $31 \%$ decrease $(\mathrm{p}<0.001)$ in the total serum antioxidant defense (measured by the total peroxyl radical trapping potential of the serum), an increase in the lipid peroxidation end products, and an accumulation of LDL cholesterol in macrophages [48].

These findings were corroborated in a similar study done in children between the ages of 9 - 13 years, comparing children who had been exposed to passive smoke in their homes of at least 10 cigarettes per day for 1 year to children who had never been exposed to passive smoke [63]. After measuring the children's total antioxidant status, the response to oxidant stress was significantly lower in children who had been exposed to SHS $(p=0.018)$ [63]. Oxidant stress was also seen in infants between the ages of 6 - 24 weeks exposed to at least 5 cigarettes per day (mean exposure of $10 \pm 3$ cigarettes per day; range 5 - 25 cigarettes per day) for the past 6 months. Infants exposed to SHS had significantly decreased levels of serum antioxidant activity, upon measurement of hydroxyl radical (1.17 $\pm 0.06 \mathrm{mmol}$ Trolox equiv./L, compared to control $1.59 \pm 0.12 \mathrm{mmol}$ Trolox equiv./L, $\mathrm{p}=0.002$ ) and a stable radical cation.

(2,2-azino-bis-3-ethylbenzothiazoline-6-sulfonic acid) (1.42 $\pm 0.22 \mathrm{mmol}$ Trolox equiv./L, compared to control $1.66 \pm 0.18 \mathrm{mmol}$ Trolox equiv./L, $\mathrm{p}=0.003$ ) [64]. Additionally, albumin (a protein with about half of the total antioxidant capacity of blood plasma) levels were significantly lower in exposed infants $(p<0.001)$, along with the decrease of other potent antioxidant molecules, such as thiol, uric acid, and bilirubin ( $\mathrm{p}=0.009, \mathrm{p}=2.57, \mathrm{p}=0.076$, respectively) [64] [65].

The association with exposure to secondhand smoke and increased cardiovascular dysfunction is also linked and exacerbated by obesity and other risk factors earlier in life. The exposure to SHS at a younger age can result in worse outcomes, as children have smaller airways and higher respiration rates, thereby causing increased SHS inhaled per unit body [62] [66]. Increased rate of smoking in parents has been associated with an increased risk of acute ischemic cerebrovascular events in children [46]. Childhood acute ischemic strokes (cerebrovascular events) are rare, associated with risk factors such as congenital heart malformations, infectious diseases, and collagen tissue diseases, but also with risk factors that are more commonly associated with atherosclerosis. These include vascular abnormalities, endothelial damage, and hypercoagulable states (such as factor V Leiden, increased lipoprotein (a) concentrations, and deficiencies of coagulation cascade inhibitors like protein $C$, protein $S$, and tissue factor pathway inhibitor) [46] [67] [68] [69] [70]. A summary of study conclusions can be found in Table 2 .

\subsection{Diabetes}

Diabetes Mellitus, both type 1 and type 2, is associated with accelerated development of vascular disease [6]. Chronic hyperglycemic states can induce 
Table 2. Summary of conclusions for passive smoking risk factor.

\begin{tabular}{|c|c|c|c|}
\hline$\underline{\text { References }}$ & Sample size & p-value & Conclusion \\
\hline \multirow[t]{2}{*}[55]{} & & $\begin{array}{c}\mathrm{p}<0.001 \\
\mathrm{p}<0.05\end{array}$ & $\begin{array}{l}\text { In adolescent males exposed to SHS, } \\
\text { increased levels of serum cotinine were } \\
\text { associated with increased deterioration of } \\
\text { cIMT and intimal smoothness. }\end{array}$ \\
\hline & & $\mathrm{p}<0.001$ & $\begin{array}{l}\text { Increased levels of serum cotinine were } \\
\text { associated with decreased vascular } \\
\text { endothelial function. }\end{array}$ \\
\hline [62] & & & $\begin{array}{l}\text { Past and current exposure to SHS is } \\
\text { associated with increased cIMT }\end{array}$ \\
\hline [48] & 10 & $\mathrm{p}<0.001$ & $\begin{array}{l}\text { Adults have a significantly decreased serum } \\
\text { antioxidant level after exposure to SHS of } \\
30 \text { minutes. }\end{array}$ \\
\hline [63] & 143 & & $\begin{array}{l}\text { Children exposed to SHS had lower } \\
\text { response to oxidant stress. }\end{array}$ \\
\hline [64] & 84 & $\mathrm{p}<0.01$ & $\begin{array}{l}\text { Infants exposed to SHS had significantly } \\
\text { decreased levels of serum antioxidants } \\
\text { (albumin, thiol, uric acid, bilirubin), and } \\
\text { significantly increased oxidative } \\
\text { metabolism byproducts. }\end{array}$ \\
\hline [46] & & & $\begin{array}{l}\text { Increased SHS exposure at home was } \\
\text { associated with increased risk of acute } \\
\text { ischemic cerebrovascular events in } \\
\text { children. }\end{array}$ \\
\hline
\end{tabular}

microangiopathic changes in the small vasculature of the eye and kidney. However, macroangiopathic changes can occur as well, and are commonly the cause of the increased morbidity and early mortality associated with diabetes; these changes manifest as cerebrovascular, cardiovascular, and peripheral vascular disease [6] [71] [72].

Type 1 diabetes can be diagnosed in both adolescents and adults. In both cases, hyperglycemia mediates atherogenesis [6]. Hyperglycemia causes reduced expression of heparan sulfate, a glycosaminoglycan component of the extracellular matrix. Decreased expression induces increased levels of apoB-containing remnant particles enriched with cholesterol [6] [73]. There is subsequently decreased clearance of these apoB particles, shown in mouse models of diabetic dyslipidemia [73]. This reduced clearance of apoB particles subsequently increases the atherogenic load [6] [73]. Paradoxically, however, adults with type 1 diabetes have a less atherogenic fasting lipid profile (with lower levels of LDL-C and TG and higher HDL-C) than those without diabetes [74].

In adolescents, Type 2 diabetes has a prevalence of approximately 4.1 to 1000 , according to data from NHANES III [6]. Type 2 diabetes diagnoses in adolescents are a relatively recent phenomenon, but share the same cardiovascular disease risks and morbidity/mortality outcomes as in the adult population [75]. 
A study done in Pima Native American Indian children aged 5 - 19 years found that those diagnosed with type 2 diabetes had a significantly higher prevalence of obesity and hypertension at diagnosis than their non-diabetic counterparts (aged 10 - 19 years old). Additionally, upon re-examination after 10 years, there was a higher prevalence of abnormal hyperalbuminuria among those children who were diagnosed with type 2 diabetes at a younger age, demonstrating a further clinical course of the disease than their counterparts [76]. This increased hyperalbuminuria in the Pima pediatric diabetic population, in both prevalence and in severity, is an increased risk for future cardiovascular events [6] [76]. In addition to hyperglycemia-mediated vascular changes, insulin resistance is also associated with hypertension, due to increased sodium retention, increased sympathetic nervous system activity, and increased stimulation of vascular smooth muscle cells [6] [77] [78]. The microvascular and microvascular changes, coupled with hypertension, place diabetic patients into a higher cardiovascular risk factor group [6].

When comparing children diagnosed with type 1 diabetes and type 2 diabetes, their cardiovascular risks and outcomes differ depending on the diagnosis made. Children diagnosed with type 1 diabetes are typically diagnosed earlier than those children diagnosed with type 2 diabetes, and are more symptomatic at diagnosis. However, with optimal and aggressive management of blood glucose levels, cardiovascular risk is reduced, and outcomes are improved. These children are considered high risk for early cardiovascular disease [6]. In contrast, children diagnosed with type 2 diabetes are not as symptomatic upon diagnosis, and have a lower atherosclerotic acceleration when compared to their type $1 \mathrm{di}$ abetic counterparts. They are still managed as high-risk patient due to the associated comorbidities of type 2 diabetes [6].

Aortic and arterial stiffness is used as a marker of cardiovascular disease, as it is a strong predictor of cardiovascular events. A study assessing arterial stiffness in children with type 1 diabetes (98 diabetic children and 57 controls; aged 10 18 years; matched for age, sex, race, and BMI (43 matched pairs)) found that children with type 1 diabetes had increased arterial stiffness compared with their healthy counterparts, upon non-invasive radial artery tonometry [79]. This was corroborated in another study of type 1 diabetic young adults (mean age $=20.8$ with mean duration of diabetes $=10$ years), where aortic pulse wave velocity (an index of aortic stiffness) was significantly increased in those with diabetes as compared to controls (diabetes mean $=4.10$; control mean $=3.90 ; \mathrm{p}-0.045$ ) [80].

Dyslipidemia is commonly found in individuals with diabetes. A Canada-based national study found that about $55 \%$ of individuals diagnosed with diabetes for over 2 years also had a diagnosis of dyslipidemia. For those with a diagnosis of over 15 years, this statistic rose to 66\% [81]. Additionally, the lipoprotein profile of an individual can be a marker of cardiovascular events, as LDL-C plays a key and obligate role in atherogenesis through its oxidation [82] [83]. HDL-C is particularly antiatherogenic, possessing antioxidant and anti-inflammatory characteristics [83]. Therefore, it follows that a lipid profile with increased levels of 
LDL-C and decreased levels of HDL-C is pro-atherogenic [74] [83]. A study assessing the subfractional components of all lipoproteins found that alterations in the fractional profile [74]. The lipoprotein classes are made up of fractions of differently sized particles, each with varying levels of activity [83]. Smaller, denser LDL particles are more pro-atherogenic because of their decreased ability to bind to the LDL receptor and increased ability to penetrate the endothelium, while larger HDL particles are more anti-atherogenic because of their increased capacity for reverse cholesterol transport and increased plasma residence time [84]. Previously reported to be found in adults with type 1 diabetes, the alteration in the subfractional components of the lipid profile can also be found in children and adolescents with type 1 diabetes, seen even just several years after diagnosis [74]. In adults, women with type 1 diabetes had both increased levels of LDL-C and smaller LDL size, while both men and women with type 1 diabetes had a more atherogenic lipid profile overall [74] [85]. Women also have a more proatherogenic lipid profile than males, with more cholesterol distributed in the smaller LDL subfractions, potentially due to increased insulin resistance [83] [86]. This atherogenic alteration in lipid profile can also be seen in adolescence, with both sexes having LDL subfractions with more cholesterol and HDL subfractions with less cholesterol, as compared to controls [74]. There were no notable differences between males and female adolescents with type 1 diabetes, but females showed lower amounts of cholesterol in VLDL for several subfractions [74]. A summary of study conclusions regarding diabetes and its association with cardiovascular disease can be found in Table 3.

There seems to be a reciprocal relationship between dyslipidemia and poor metabolic control in adolescents: it has been shown that unhealthy diets that lead to increased BMI will result in increased lipid levels and poor metabolic control [87]. Additionally, this effect can be heightened in post-pubertal female

Table 3. Summary of conclusions for diabetes risk factor.

\begin{tabular}{|c|c|c|c|}
\hline References & Sample size & p-value & Conclusions \\
\hline$[76]$ & 4738 & & $\begin{array}{l}\text { Pima Indian children diagnosed with type } 2 \\
\text { diabetes mellitus at an earlier age had a increased } \\
\text { rate of worsening hyperalbuminuria, when } \\
\text { compared to their peers diagnosed at a later age. }\end{array}$ \\
\hline [79] & 98 & $\mathrm{p}=0.0031$ & $\begin{array}{l}\text { Children diagnosed with type } 1 \text { diabetes mellitus } \\
\text { have increased arterial stiffness. }\end{array}$ \\
\hline [80] & 80 & $\mathrm{p}=0.045$ & $\begin{array}{l}\text { Young adults diagnosed with type } 1 \text { diabetes } \\
\text { mellitus have increased aortic stiffness. }\end{array}$ \\
\hline [74] & 45 & $\mathrm{p}<0.05$ & $\begin{array}{l}\text { Adolescents with type } 1 \text { diabetes had higher } \\
\text { LDL-C lipid subfractions and lower HDL-C lipid } \\
\text { subfractions than their non-diabetic counterparts. } \\
\text { Female adolescents with type } 1 \text { diabetes have lower } \\
\text { amounts of cholesterol in VLDL for several lipid } \\
\text { subfractions. }\end{array}$ \\
\hline
\end{tabular}


adolescents with type 1 diabetes mellitus, with low physical activity being linked more strongly to poor metabolic control than unhealthy diet [88]. Experimental animal models have demonstrated the effect of early obesity (with a high calorie, high fat diet) on increased endothelial dysfunction and vascular oxidative stress, even before the development of insulin resistance [89] [90]. Studies done in adolecents have further shown a significant association between increased oxidative stress and hypertension, independent of BMI, and between increased oxidative stress, adiposity and insulin resistance [89] [91] [92]. Adolescents between $5^{\text {th }}-8^{\text {th }}$ grades that were above the median BMI for their age groups showed a significant increase in their systolic blood pressure $(\mathrm{p}=0.0009)$, fasting insulin $(\mathrm{p}=0.0001)$, and TG $(\mathrm{p}=0.0002)$, and a significant decrease in their HDL-C ( $\mathrm{p}$ $=0.007$ ) [92]. Additionally, adolescents who were both above the median BMI for their age group and resistant to insulin had significant had significantly higher levels of TG and lower levels of HDL-C than their insulin-sensitive counterparts [92].

An inverse relationship between the prevalence of type 2 diabetes and FH has been seen in an observational study. Researchers found that type 2 diabetes was less prevalent in patients with $\mathrm{FH}$ than their unaffected relatives $(1.75 \%$ vs. $2.93 \%$ in unaffected relatives; $\mathrm{p}<0.001$ ) [93]. Opposite to the mechanism of $\mathrm{FH}$ is the mechanism of statin drugs [93]. Extensive research has been done on exposure to statins and the prevalence of type 2 diabetes; it has been seen in several studies that statins increase the risk of type 2 diabetes, with higher doses of statins posing a greater risk than moderate doses [94] [95]. The exact mechanism of this increased risk is unclear, however there are hypotheses related to the relationship between increased risk of type 2 diabetes and increased intracellular cholesterol levels as a result of statins [93] [94]. The possibility of this relationship is strengthened by the inverse relationship between the prevalence of type 2 diabetes and $\mathrm{FH}$; the mechanisms of statin drugs and $\mathrm{FH}$ are exactly opposite to each other [93]. Several studies have reported a 9\% increase in the risk of type 2 diabetes prevalence during statin use [94] [96] [97]. Studies have shown that pancreatic beta islet cells are negatively affected by the presence of increased LDL-C, in an LDL-R dependent manner [93] [98] [99] [100]. In addition, HDL-C has been shown to have a protective effect on pancreatic beta islet cells, by decreasing apoptosis of the islet cells induced by both IL-1beta and glucose [100]. A study assessing the prodiabetogenic risk of statin use in FH concluded that long-term use (mean duration of treatment $=10$ years) of high dose statins in patients with molecularly-diagnosed $\mathrm{FH}$ (age $\geq 18$ years) does not increase the risk of developing type 2 diabetes [101]. Positive predictors of type 2 diabetes in FH patients are increasing age (from ages 50 - 75 years) and the presence of metabolic syndrome, also positive predictors in the general population [101].

\subsection{Hypertension/Obesity/Elevated Lipids}

Hypertension is a powerful contributor to the development of atherosclerosis in 
adults, and is often found alongside other conditions such as diabetes, dyslipidemia, and obesity, among others [102]. In a long-term study measuring individuals' serum lipid levels, blood pressure, and BMI over a period of 27 years, it was found that blood pressure measurements during childhood (between the age of 3 and 18) were predictive of hypertension in adulthood [103]. This association held true for serum TG levels and body mass index as well [103]. These risk factors (hypertension, hypertriglyceridemia, and obesity) are highly associated with cardiovascular disease and coronary artery disease, and are influential in the development and progression of atherosclerosis.

One study assessing the incidence of cardiovascular accidents in adult patients (both male and female caucasians, all above the age of 45) with chronic renal failure re-established that cigarette smoking was a very significant independent risk factor for renal artery stenosis: patients that experienced cardiovascular events had a cumulative pack-year history of smoking that was three times higher than those without cardiovascular events [104]. This study also postulated that cigarette smoke's atherogenicity was higher in patients with uremic dylipidemia because of the increased generation of free radicals and lipid peroxidation, adding to the atherogenic load already present in uremic patients [104] [105]. Another major independent risk factor established was uremic dyslipidemia, namely, increased TC, LDL-C, apoB, and TG levels, and decreased HDL levels [104]. If lipid measurements taken during childhood years are predictive of lipid levels in adulthood, it follows that elevated childhood lipid levels increase a patient's risk for cardiovascular events in the setting of chronic renal failure, which has an estimated prevalence in the United States of about 14\% [106].

Another study found that an elevated blood pressure was more prevalent in overweight children and adolescents, and increased as obesity increased in severity [107]. Obesity and hypertension have been cited as two of the most influential risk factors in the development of cardiovascular disease in both adults and children [108] [109]. In a meta-analysis of 15 studies, and using left ventricular hypertrophy (LVH) as a marker of hypertensive cardiovascular disease, the odds ratio of having LVH was 4.19 times higher in obese patients than non obese patients [108].

Additionally, studies such as the Bogalusa Heart Study have found that childhood BMI and blood pressure are highly predictive of the effects of cardiovascular disease, including left ventricular hypertrophy and changes in left ventricular geometric patterns [110] [111] [112] [113]. The Muscatine study found an association between elevated childhood BMI and an increased risk for carotid artery thickening in women [38] [39]. These findings together provide support for the argument to begin intervention in at risk children from an earlier age, but also to increase screening to detect higher risk children earlier in their lives, all in order to mitigate the effects of these risk factors later in life. These risk factors seen in children and young adults are highly predictive of adult cardiovascular outcome, and over time, the burden of cardiovascular disease increases [109]. 
The Muscatine study found that elevated childhood TC level was a significant independent risk factor for carotid artery thickening during adulthood for both men and women [38] [39]. The Bogalusa study found that any single measurement of elevated LDL-C level and BMI in childhood years was associated with an increased carotid intimal-medial thickness in young adults [40]. These results are consistent with autopsy results showing an association between TC or LDL-C levels with extent of atherosclerotic lesions in all ages, from infancy to adolescence [40]. A summary of study conclusions regarding hypertension, dyslipidemia, and obesity, and their associations with cardiovascular disease can be found in Table 4.

\subsection{Lifestyle}

\subsubsection{Physical Activity}

Physical activity and exercise has been shown to decrease the pathogenesis and symptoms of individuals with dyslipidemia, and reduce cholesterol levels [114] [115]. Multiple cross-sectional studies have shown the association between physical activity, increased arterial elasticity and compliance, and decreased stiffening in all ages, from children to older adults [115] [116] [117] [118]. In adults, it has been shown that increased physical activity is associated with increased insulin sensitivity, a less atherogenic lipid profile, decreased incidence of metabolic syndrome, and a lower blood pressure [115]. A cross-sectional study of adults ( $\mathrm{n}=135$; age 20 - 40 years; 67 females) demonstrated lower arterial compliance in sedentary adults, as compared to their endurance-trained peers [119]. A summary of study conclusions regarding the relationship between physical activity and cardiovascular findings can be found in Table 5 .

\subsubsection{Diet}

Diet has been shown to be an independent risk factor affecting cardiovascular risk. A study showed that adiposity and the lipid-to-carbohydrate intake ratio were independent risk factors for cardiovascular risk, after being adjusted for age, gender, and duration of type 1 diabetes. This study was conducted in children and adolescents diagnosed with type 1 diabetes, yet regardless of HbAlc levels (a marker of severity and duration of hyperglycemia), the lipid-to-carbohydrate intake ratio independently affected the individual's non-HDL-C [120]. In these study subjects (age $<18 \mathrm{yr}$, Caucasian, type 1 diabetes onset $>1 \mathrm{yr}$ prior to recruitment, and confirmation of diagnosis; $\mathrm{n}=180$ ), non-HDL-C was associated with an increased lipid-to-carbohydrate intake ratio, with an increase in non-HDL-C associated with lipid intake, and a decrease in non-HDL-C associated with carbohydrate [120]. It follows, therefore, that efforts should be made to both control blood glucose in patients diagnosed with type 1 diabetes, but also to control the macronutrient intake of the diet [120]. A summary of study conclusions regarding dietary intake and its association with cardiovascular disease can be found in Table 6 . 
Table 4. Summary of study conclusions for hypertension, obesity, and hyperlipidemia risk factors.

\begin{tabular}{|c|c|c|c|}
\hline$\underline{\text { Reference }}$ & Sample size & p-value & Conclusion \\
\hline [92] & 295 & & $\begin{array}{l}\text { Adolescents above median BMI for their age had increased } \\
\text { systolic blood pressure }(\mathrm{p}=0.0009) \text {, fasting insulin }(\mathrm{p}=0.0001) \text {, } \\
\text { and TG ( } \mathrm{p}-0.0002) \text {, and decreased HDL-C }(\mathrm{p}=0.007) \text {. } \\
\text { Insulin-resistant adolescents above the median BMI for their age } \\
\text { had higher TG and lower HDL-C than their insulin-sensitive } \\
\text { counterparts. }\end{array}$ \\
\hline [103] & 2204 & $\mathrm{p}<0.0001$ & $\begin{array}{l}\text { Increased adolescent measurements of systolic blood pressure, } \\
\text { serum TG levels, and BMI were predictive of hypertension in } \\
\text { adulthood. }\end{array}$ \\
\hline [107] & 497 & & $\begin{array}{l}\text { The severity of child and adolescent systolic }(\mathrm{p}<0.001) \text { and } \\
\text { diastolic }(\mathrm{p}<0.01) \text { hypertension is positively correlated with the } \\
\text { severity of obesity. }\end{array}$ \\
\hline [108] & 5486 & $\mathrm{p}<0.01$ & $\begin{array}{l}\text { The odds of having left ventricular hypertrophy were } 4.19 \text { times } \\
\text { higher in obese patients than non-obese patients. }\end{array}$ \\
\hline [110] & 467 & $\mathrm{p}<0.001$ & $\begin{array}{l}\text { In children, increasing BMI was positively correlated with } \\
\text { increasing left ventricular mass. }\end{array}$ \\
\hline [111] & 824 & $\mathrm{p}=0.001$ & $\begin{array}{l}\text { In young adults, BMI was positively correlated with eccentric left } \\
\text { ventricular hypertrophy. }\end{array}$ \\
\hline [112] & 160 & $\mathrm{p}<0.2$ & $\begin{array}{l}\text { In children, excess weight may correlate to left ventricular } \\
\text { hypertrophy beyond normal cardiac growth. }\end{array}$ \\
\hline [113] & 343 & & $\begin{array}{l}\text { Obese African-American adolescents had significantly higher left } \\
\text { ventricular mass }(p=0.01) \text { and wall thickness }(p<0.001) \text { as } \\
\text { compared to their non-obese counterparts. }\end{array}$ \\
\hline [39] & 769 & $\begin{array}{c}\text { Men: } \mathrm{p}=0.002 \\
\text { Women: } \mathrm{P}=0.009 \\
\qquad \mathrm{p}<0.01\end{array}$ & $\begin{array}{l}\text { Childhood TC levels are significantly correlated with increased } \\
\text { cIMT in both adult men and women. } \\
\text { Childhood BMI is significantly correlated with increased cIMT in } \\
\text { adult women. }\end{array}$ \\
\hline [40] & 486 & $\mathrm{p}<0.001$ & $\begin{array}{l}\text { Any single measurement of elevated LDL-C or BMI in childhood } \\
\text { is associated with increased cIMT in adulthood. }\end{array}$ \\
\hline
\end{tabular}

Table 5. Summary of study conclusions for physical activity risk factor.

\begin{tabular}{|c|c|c|c|}
\hline$\underline{\text { Reference }}$ & Sample size & $\mathrm{p}$-value & Conclusion \\
\hline [115] & 2416 & & $\begin{array}{l}\text { Physical activity in male children and young adults is associated } \\
\text { with increased carotid distensibility }(\mathrm{p}=0.014) \text {, decreased } \\
\text { Young's elastic modulus }(\mathrm{p}=0.0037) \text {, and decreased stiffness ( } \mathrm{p}= \\
0.0028) \text { when measured } 21 \text { years later. }\end{array}$ \\
\hline [116] & 12 & $\mathrm{p}<0.05$ & $\begin{array}{l}\text { After a 3-month aerobic exercise program, previously sedentary } \\
\text { adult postmenopausal women on hormone replacement therapy } \\
\text { had significantly increased arterial compliance (indistinguishable } \\
\text { from premenopausal women). }\end{array}$ \\
\hline [117] & 45 & $\mathrm{p}<0.05$ & $\begin{array}{l}\text { Carotid arterial compliance is higher in those adults who perform } \\
\text { aerobic exercise (swimming, running) when compared to } \\
\text { sedentary controls. }\end{array}$ \\
\hline [118] & 538 & $\mathrm{p}<0.05$ & $\begin{array}{l}\text { Less time spent in light physical activity is associated with } \\
\text { increased carotid femoral pulse wave velocity in older adult men } \\
\text { and women. }\end{array}$ \\
\hline
\end{tabular}


Table 6. Summary of study conclusions for dietary intake risk factor.

\begin{tabular}{|c|c|c|c|}
\hline References & $\underline{\text { Sample size }}$ & p-value & Conclusions \\
\hline [120] & 180 & $\mathrm{p}=0.007$ & $\begin{array}{l}\text { Dietary lipid-to-carbohydrate intake ratio affects } \\
\text { non-HDL-C levels (independent of HbAlc levels). } \\
\text { Increased lipid intake is associated with increased } \\
\text { non-HDL-C levels. }\end{array}$ \\
\hline
\end{tabular}

\section{Current Practice}

\subsection{Screening}

Current recommendations include screening children and adolescents for dyslipidemia through a universal method of screening children between the ages of 9 - 11. This age range was selected because this is the period in which the atherosclerotic effects of dyslipidemia in patients with $\mathrm{HeFH}$ appear more rapidly; it is also before the natural pubertal decline of LDL-C [121] [122]. The recommendations also call for a second screening between ages 17 and 21 after puberty has occurred, again to mitigate the natural fluctuations of lipid levels during growth and maturity [123] [124].

Though FH has and requires aggressive treatment options, it is often underdiagnosed and undertreated, as evidenced by a follow-up study performed after children were diagnosed with $\mathrm{FH}$; though there is a recommendation in place to refer screened children deemed at-risk to a pediatrician or specialized lipid clinic, only $51 \%$ of patients were referred, and only $29 \%$ attended a specialized lipid clinic [125].

There are several screening strategies in place for FH. In the adult population, a systematic cascade screen of probands has proven to be more efficient and cost-effective than universal screening, which can pose as impractical and economically unfeasible [11] [126]. A 2014 Australian-based study concluded that integrating both genetic and phenotypic cascade screening in at-risk families was most cost effective [11].

\subsection{Diagnosis}

Especially in the pediatric population, $\mathrm{FH}$ is underdiagnosed and undertreated, with estimates that only about $20 \%$ of pediatric cases are diagnosed [5] [125] [127]. Diagnosing FH is based upon a multitude of findings, including family history, clinical signs (such as tendinous xanthomas, xanthelasmas, and corneal arcus), and cholesterol concentrations [127] [128]. Additionally, secondary causes for hypercholesterolemia should be excluded before considering a diagnosis of FH [127].

Several sets of criteria have been created for the diagnosis of $\mathrm{FH}$, and are used in different ways internationally. Common and validated criteria include MEDPED (Make Early Diagnosis to Prevent Early Death) in the United States, Simon-Broome in the United Kingdom, and the Dutch Lipid Clinic criteria [127] [128] [129]. The MEDPED criteria specifies cutpoints for TC levels that are specific to an individu- 
al's age and family history [129] [130]. The Simon z-Broome Register criteria includes concentrations of cholesterol, clinical findings, family history, and molecular diagnosis, and categorizes the FH diagnosis as "definite" or "probable" [130] [131]. The Dutch Lipid Clinic Network criteria assign points for family history, clinical characteristics, LDL-C levels, and any identified mutation, and considers FH to be "definite," "probable," or "possible" [130].

In order to ascertain the specific cause of FH in a patient, DNA tests are used to look for mutations, deletions, or rearrangements in the three genes commonly related to FH (LDLR, ApoB, and PCSK9) [132]. This additionally creates a more definitive diagnosis.

\subsection{Interventions/Treatments}

For screened children with elevated LDL-C levels, the current 2011 guidelines first recommend a lifestyle change, with an emphasis on dietary management [121] [122]. For children with a high TG and low HDL-C profile, the guideline's lifestyle management recommendation includes an emphasis on diet and physical activity, with additional pharmacological interventions, including statins, recommended for those with a notably elevated LDL-C [121]. Lipid lowering agents are currently not recommended in children under the age of 10 , unless in the presence of a severe primary hyperlipidemia or a very high-risk cardiovascular profile [121]. Lipid lowering agents are, however, recommended in children above the age of 10, after adequate dietary and lifestyle management has been attempted without success [121] [133]. Specific treatment courses and pharmacologic agents chosen are based on a thorough assessment of associated risk factors and lipid profile [121].

The pharmacological mainstay for treatment of dyslipidemia in both children and adults is the use of HMG-CoA reductase inhibitors ("statins") to downregulate the synthesis of cholesterol at the rate-limiting step, resulting in the sensitization of the LDL receptors in hepatic tissues and further reducing the levels of LDL circulating in the plasma [37] [124] [134]. Statins have been shown to improve endothelial function in vascular tissue by way of two independent mechanisms: the previously mentioned reduction of serum cholesterol levels, and also directly at the vascular wall [134] [135] [136]. The full mechanism behind the effect of statins on the vascular wall is not fully understood, but may be related to the upregulation of nitric oxide synthase activity, causing vascular vasodilation [136]. Since their introduction and implementation, statins have been associated with an increased prognosis for patients with $\mathrm{HeFH}$, with a reduction in the relative risk of death from a cardiovascular event [21] [137]. A prospective study examining mortality rates in statin-treated patients with $\mathrm{HeFH}$ conducted between 1980 and 2006 showed a statistically significant CHD mortality rate reduction of $37 \%(\mathrm{p}=0.01)$, with relative risks decreasing from 3.4 to 2.1 [21]. Primary prevention of statin administration resulted in a $48 \%$ reduction in mortality, while patients with established cardiovascular disease demonstrated a $25 \%$ 
reduction of mortality (from 5.2-3.9-fold excess) [21]. This suggests that earlier diagnosis of $\mathrm{HeFH}$ (also used as a surrogate for hyperlipidemias), and implementation of primary prevention rather than secondary prevention, can result in a reduction of early coronary mortality associated with hyperlipidemia. Additionally, implementation of pharmacological interventions in patients with established disease requires more intense treatment to reduce mortality rates [21]. A Netherland-based study aimed to see the effects of rosuvastatin, an extremely effective statin used to control hyperlipidemias in adults, on children between the ages of 6 and 17 with HeFH. Researchers found that the rate of progression of atherosclerosis in these children decreased when exposed to statins, as compared to their untreated affected siblings, through measurements of the carotid artery intima-media thickness [138]. Additionally, the age of statin treatment initiation has been positively associated with cardiovascular health: earlier age of statin initiation in patients with a family history and personal history of $\mathrm{FH}$ is associated with a smaller carotid intima-media thickness upon follow-up [139].

In adults, statins are tolerated well, with rare side effects occurring only at very high doses, and even more rarely at lower doses. Some of these rare side effects include hepatotoxicity, myopathy, and myotoxicity, and can be as a result of drug metabolism interactions, espcially with the cytochrome P-450 enzyme system [140] [141]. In children, numerous statins are approved in the United States and in Europe for use in FH in pediatric patients [37]. These include simvastatin, lovastatin, atorvastatin, pravastatin, fluvastatin, and rusuvastatin; all of the aforementioned are approved in children from the age of 10 , with the exception of pravastatin, approved in children from age 8 [37].

Meta-analyses of studies assessing the effects of statins in pediatric populations have shown a statistically significant increase in HDL levels and a statistically significant decrease in both LDL and TC levels when compared to a placebo [142]. The use of statins in children has not presented increased safety risk in studies when compared with the administration of a placebo; however, there is very little data demonstrating the effects of exposure to statins longer than 2 years in children [15]. The short-term safety and efficacy of statins has been demonstrated in numerous studies and meta-analyses, including the effect of statins on the production of steroid sex hormones [37] [143]. One study found that, upon follow-up of pediatric $\mathrm{FH}$ patients on a statin regimen, there seemed to be no statistically significant effect of statins on sexual growth and maturation, when compared to reference values [139]. When compared to children between the ages of 8 and 18 taking plecebos, pediatric subjects receiving a statin intervention had no significant difference in levels of dehydroepiandrosterone sulfate and cortisol, and no changes from baseline values [144]. Another meta-analysis evaluating the effects of statins on children between the ages of 8 and 18 years found that there were no statistically significant differences between children treated with statins and those treated with placebos in terms of adverse effects, changes in sexual development, muscle toxicity, or liver toxicity [143]. 
Another class of drugs used to reduce LDL-C in patients is bile acid sequestrants, of which ezetimibe and colesevelam are approved for use in children from the age of 10 in the United States. Both drugs have been shown to significantly lower LDL-C levels in the pediatric population, with minimal adverse side effects [143] [145]. Co-administration of both ezetimibe and simvastatin was shown to have a significantly better outcome than administration of simvastatin alone; children between the ages of 10 and 17 (inclusive) receiving the dual therapy of ezetimibe and simvastatin had a mean reduction of LDL-C of $54.0 \%$, while their simvastatin monotherapy counterparts had a mean reduction of $38.1 \%(\mathrm{p}<0.01)$ [143] [146].

\section{Conclusion}

Risk factors for dyslipidemia and development of cardiovascular disease and atherosclerosis are similar in children, adolescents, and adults. However, the effects of various insults to the vasculature can be observed as early as in pediatric years. When seen in early life, these modifiable risk factors often have an augmented effect throughout childhood and into adulthood, though the overall pathogenesis and consquences of the risk factors are the same in both children and adults. By understanding these risk factors as they relate to children and adolescents, lifestyle modifications can be made earlier in life by both children and their families to reduce the progression of dyslipidemia and atherosclerosis in children and adolescents. Additionally, a comprehensive understanding of the effects and safety profiles of pharmacological treatment, and its translation to significantly reduced morbidity and mortality later in life can promote earlier screening and treatment in the pediatric population, eventually working to reduce the burden of dyslipidemia on our population.

\section{Methods}

A literature review was conducted using computerized databases (PubMed, MEDLINE, Ovid, Wiley Online Library) and a references list search. Articles were included based on their type, objective, and target sample and audience. An effort was made to concentrate selected articles on those targeting a pediatric sample. However some concepts were related using both pediatric and adult models. A selection of both primary literature and review articles was used to compile the information presented; review articles were used as a foundation upon which to build a repertoire of primary literature sources.

\section{References}

[1] Centers for Disease Control and Prevention (2015) High Cholesterol Facts. https://www.cdc.gov/cholesterol/facts.htm

[2] Bibbins-Domingo, K., Grossman, D.C., Curry, S.J., Davidson, K.W., Epling, J.W., García, F.A.R., et al. (2016) Screening for Lipid Disorders in Children and Adolescents: US Preventive Services Task Force Recommendation Statement. JAMA, 316, 625-633. https://doi.org/10.1001/jama.2016.9852 
[3] Gultom, L.C., Sjarif, D.R., Sudoyo, H.A., Mansyur, M., Hadinegoro, S.R.S., Immanuel, S., et al. (2015) The Role of Apolipoprotein E Polymorphism in Improving Dyslipidemia in Obese Adolescents Following Physical Exercise and National Cholesterol Education Program Step II Intervention. Journal of Pediatric Endocrinology and Metabolism, 28, 597-603. https://doi.org/10.1515/jpem-2014-0070

[4] Asselbergs, F.W., Guo, Y., van Iperen, E.P.A., Sivapalaratnam, S., Tragante, V., Lanktree, M.B., et al. (2012) Large-Scale Gene-Centric Meta-Analysis across 32 Studies Identifies Multiple Lipid Loci. The American Journal of Human Genetics, 91, 823-838. https://doi.org/10.1016/j.ajhg.2012.08.032

[5] Goldberg, A.C., Hopkins, P.N., Toth, P.P., Ballantyne, C.M., Rader, D.J., Robinson, J.G., et al. (2011) Familial Hypercholesterolemia: Screening, Diagnosis and Management of Pediatric and Adult Patients. Journal of Clinical Lipidology, 5, 133-140. https://doi.org/10.1016/j.jacl.2011.03.001

[6] Kavey, R.-E.W., Allada, V., Daniels, S.R., Hayman, L.L., McCrindle, B.W., Newburger, J.W., et al. (2006) Cardiovascular Risk Reduction in High-Risk Pediatric Patients. A Scientific Statement from the American Heart Association Expert Panel on Population and Prevention Science, the Councils on Cardiovascular Disease in the Young, Epidemiology and Prevention, Nutrition, Physical Activity and Metabolism, High Blood Pressure Research, Cardiovascular Nursing, and the Kidney in Heart Disease, and the Interdisciplinary Working Group on Quality of Care and Outcomes Research: Endorsed by the American Academy of Pediatrics. Circulation, 114, 2710-2738. https://doi.org/10.1161/CIRCULATIONAHA.106.179568

[7] Marks, D., Thorogood, M., Neil, H.A.W. and Humphries, S.E. (2003) A Review on the Diagnosis, Natural History, and Treatment of Familial Hypercholesterolaemia. Atherosclerosis, 168, 1-14. https://doi.org/10.1016/S0021-9150(02)00330-1

[8] Pang, J., Martin, A.C., Mori, T.A., Beilinm, L.J. and Watts, G.F. (2016) Prevalence of Familial Hypercholesterolemia in Adolescents: Potential Value of Universal Screening? Journal of Pediatrics, 170, 315-316. https://doi.org/10.1016/j.jpeds.2015.11.019

[9] Benn, M., Watts, G.F., Tybjærg-Hansen, A. and Nordestgaard, B.G. (2016) Mutations Causative of Familial Hypercholesterolaemia: Screening of 98,098 Individuals from the Copenhagen General Population Study Estimated a Prevalence of 1 in 217. European Heart Journal, 37, 1384-1394. https://doi.org/10.1093/eurheartj/ehw028

[10] de Ferranti, S.D., Rodday, A.M., Mendelson, M.M., Wong, J.B., Leslie, L.K. and Sheldrick, R.C. (2016) Prevalence of Familial Hypercholesterolemia in the 1999 to 2012 United States National Health and Nutrition Examination Surveys (NHANES). Circulation, 133, 1067-1072. https://doi.org/10.1161/CIRCULATIONAHA.115.018791

[11] Ademi, Z., Watts, G.F., Pang, J., Sijbrands, E.J.G., van Bockxmeer, F.M., O’Leary, P., et al. (2014) Cascade Screening Based on Genetic Testing Is Cost-Effective: Evidence for the Implementation of Models of Care for Familial Hypercholesterolemia. Journal of Clinical Lipidology, 8, 390-400. https://doi.org/10.1016/j.jacl.2014.05.008

[12] Nordestgaard, B.G., Chapman, M.J., Humphries, S.E., Ginsberg, H.N., Masana, L., Descamps, O.S., et al. (2013) Familial Hypercholesterolaemia Is Underdiagnosed and Undertreated in the General Population: Guidance for Clinicians to Prevent Coronary Heart Disease Consensus Statement of the European Atherosclerosis Society. European Heart Journal, 34, 3478-3490.

https://doi.org/10.1093/eurheartj/eht273

[13] Santos, R.D., Gidding, S.S., Hegele, R.A., Cuchel, M.A., Barter, P.J., Watts, G.F., et al. (2016) Defining Severe Familial Hypercholesterolaemia and the Implications for 
Clinical Management: A Consensus Statement from the International Atherosclerosis Society Severe Familial Hypercholesterolemia Panel. Lancet Diabetes and Endocrinology, 4, 850-861. https://doi.org/10.1016/S2213-8587(16)30041-9

[14] Leigh, S., Futema, M., Whittall, R., Taylor-Beadling, A., Williams, M., den Dunnen, J.T., et al. (2017) The UCL Low-Density Lipoprotein Receptor Gene Variant Database: Pathogenicity Update. Journal of Medical Genetics, 54, 17-23. https://doi.org/10.1136/jmedgenet-2016-104054

[15] Ross, J.L. (2016) Statins in the Management of Pediatric Dyslipidemia. Journal of Pediatric Nursing, 31, 723-735. https://doi.org/10.1016/j.pedn.2016.07.004

[16] Futema, M., Shah, S., Cooper, J.A., Li, K., Whittall, R.A., Sharifi, M., et al. (2015) Refinement of Variant Selection for the LDL Cholesterol Genetic Risk Score in the Diagnosis of the Polygenic Form of Clinical Familial Hypercholesterolemia and Replication in Samples from 6 Countries. Clinical Chemistry, 61, 231-238. https://doi.org/10.1373/clinchem.2014.231365

[17] Futema, M., Whittall, R.A., Kiley, A., Steel, L.K., Cooper, J.A., Badmus, E., et al. (2013) Analysis of the Frequency and Spectrum of Mutations Recognised to Cause Familial Hypercholesterolaemia in Routine Clinical Practice in a UK Specialist Hospital Lipid Clinic. Atherosclerosis, 229, 161-168.

https://doi.org/10.1016/j.atherosclerosis.2013.04.011

[18] Al Kindi, M., Bélanger, A.M., Sayegh, K., Senouci, S., Aljenedil, S., Sivakumaran, L., et al. (2017) Aortic Calcification Progression in Heterozygote Familial Hypercholesterolemia. Canadian Journal of Cardiology, 33, 658-665. https://doi.org/10.1016/j.cjca.2017.02.001

[19] Al-Shaikh, A.M., Abdullah, M.H., Barclay, A., Cullen-Dean, G. and McCrindle, B.W. (2002) Impact of the Characteristics of Patients and Their Clinical Management on Outcomes in Children with Homozygous Familial Hypercholesterolemia. Cardiology in the Young, 12, 105-112. https://doi.org/10.1017/S1047951102000240

[20] Fantus, D., Awan, Z., Seidah, N.G. and Genest, J. (2013) Aortic Calcification: Novel Insights from Familial Hypercholesterolemia and Potential Role for the Low-Density Lipoprotein Receptor. Atherosclerosis, 226, 9-15. https://doi.org/10.1016/j.atherosclerosis.2012.08.026

[21] Neil, A., Cooper, J., Betteridge, J., Capps, N., McDowell, I., Durrington, P., et al. (2008) Reductions in All-Cause, Cancer, and Coronary Mortality in Statin-Treated Patients with Heterozygous Familial Hypercholesterolaemia: A Prospective Registry Study. European Heart Journal, 29, 2625-2633. https://doi.org/10.1093/eurheartj/ehn422

[22] Awan, Z., Alrasadi, K., Francis, G.A., Hegele, R.A., McPherson, R., Frohlich, J., et al. (2008) Vascular Calcifications in Homozygote Familial Hypercholesterolemia. Arteriosclerosis, Thrombosis, and Vascular Biology, 28, 777-785. https://doi.org/10.1161/ATVBAHA.107.160408

[23] Khera, A.V., Won, H.-H., Peloso, G.M., Lawson, K.S., Bartz, T.M., Deng, X., et al. (2016) Diagnostic Yield and Clinical Utility of Sequencing Familial Hypercholesterolemia Genes in Patients with Severe Hypercholesterolemia. Journal of the American College of Cardiology, 67, 2578-2589. https://doi.org/10.1016/j.jacc.2016.03.520

[24] Mallika, V., Goswami, B. and Rajappa, M. (2007) Atherosclerosis Pathophysiology and the Role of Novel Risk Factors: A Clinicobiochemical Perspective. Angiology, 58, 513-522. https://doi.org/10.1177/0003319707303443

[25] Berenson, G.S., Srinivasan, S.R., Bao, W., Newman, W.P., Tracy, R.E. and Wattigney, W.A. (1998) Association between Multiple Cardiovascular Risk Factors and 
Atherosclerosis in Children and Young Adults. The New England Journal of Medicine, 338, 1650-1656. https://doi.org/10.1056/NEJM199806043382302

[26] Moore, K.J. and Tabas, I. (2011) Macrophages in the Pathogenesis of Atherosclerosis. Cell, 145, 341-355. https://doi.org/10.1016/j.cell.2011.04.005

[27] Stary, H.C., Chandler, A.B., Glagov, S., Guyton, J.R., Insull, W., Rosenfeld, M.E., et al. (1994) A Definition of Initial, Fatty Streak, and Intermediate Lesions of Atherosclerosis. A Report from the Committee on Vascular Lesions of the Council on Arteriosclerosis, American Heart Association. Circulation, 89, 2462-2478. https://doi.org/10.1161/01.CIR.89.5.2462

[28] Libby, P., Ridker, P.M. and Hansson, G.K. (2009) Inflammation in Atherosclerosis: From Pathophysiology to Practice. Journal of the American College of Cardiology, 54, 2129-2138. https://doi.org/10.1016/j.jacc.2009.09.009

[29] Rudzka, D.A., Cameron, J.M. and Olson, M.F. (2015) Reactive Oxygen Species and Hydrogen Peroxide Generation in Cell Migration. Communicative \& Integrative Biology, 8, e1074360.

[30] Steinberg, D. (1997) Lewis, A. Conner Memorial Lecture. Oxidative Modification of LDL and Atherogenesis. Circulation, 95, 1062-1071.

https://doi.org/10.1161/01.CIR.95.4.1062

[31] Brown, M.S. and Goldstein, J.L. (1983) Lipoprotein Metabolism in the Macrophage: Implications for Cholesterol Deposition in Atherosclerosis. Annual Review of Biochemistry, 52, 223-261. https://doi.org/10.1146/annurev.bi.52.070183.001255

[32] Van Gaal, L.F., Mertens, I.L. and De Block, C.E. (2006) Mechanisms Linking Obesity with Cardiovascular Disease. Nature, 444, 875-880. https://doi.org/10.1038/nature05487

[33] Stary, H.C., Chandler, A.B., Dinsmore, R.E., Fuster, V., Glagov, S., Insull, W., et al. (1995) A Definition of Advanced Types of Atherosclerotic Lesions and a Histological Classification of Atherosclerosis. A Report from the Committee on Vascular Lesions of the Council on Arteriosclerosis, American Heart Association. Circulation, 92, 1355-1374. https://doi.org/10.1161/01.CIR.92.5.1355

[34] Khoury, Z., Schwartz, R., Gottlieb, S, Chenzbraun, A., Stern, S. and Keren, A. (1997) Relation of Coronary Artery Disease to Atherosclerotic Disease in the Aorta, Carotid, and Femoral Arteries Evaluated by Ultrasound. American Journal of Cardiology, 80, 1429-1433. https://doi.org/10.1016/S0002-9149(97)00701-7

[35] Bridger, T. (2009) Childhood Obesity and Cardiovascular Disease. Paediatrics \& Child Health, 14, 177-182. https://doi.org/10.1093/pch/14.3.177

[36] Wissler, RW. (1991) USA Multicenter Study of the Pathobiology of Atherosclerosis in Youtha. Annals of the New York Academy of Sciences, 623, 26-39. https://doi.org/10.1111/j.1749-6632.1991.tb43716.x

[37] Wiegman, A., Gidding, S.S., Watts, G.F., Chapman, M.J., Ginsberg, H.N., Cuchel, M., et al. (2015) Familial Hypercholesterolaemia in Children and Adolescents: Gaining Decades of Life by Optimizing Detection and Treatment. European Heart Journal, 36, 2425-2437. https://doi.org/10.1093/eurheartj/ehv157

[38] Groner, J.A., Joshi, M. and Bauer, J.A. (2006) Pediatric Precursors of Adult Cardiovascular Disease: Noninvasive Assessment of Early Vascular Changes in Children and Adolescents. Pediatrics, 118, 1683-1691.

https://doi.org/10.1542/peds.2005-2992

[39] Davis, P.H., Dawson, J.D., Riley, W.A. and Lauer, R.M. (2001) Carotid Intimal-Medial Thickness Is Related to Cardiovascular Risk Factors Measured from 
Childhood through Middle Age: The Muscatine Study. Circulation, 104, 2815-2819. https://doi.org/10.1161/hc4601.099486

[40] Li, S., Chen, W., Srinivasan, S.R., Bond, M.G., Tang, R., Urbina, E.M., et al. (2003) Childhood Cardiovascular Risk Factors and Carotid Vascular Changes in Adulthood: The Bogalusa Heart Study. JAMA, 290, 2271-2276.

https://doi.org/10.1001/jama.290.17.2271

[41] Prastyanto, S., Sitaresmi, M.N. and Julia, M. (2014) Lipid Profiles in Smoking and Non-Smoking Male Adolescents. Paediatrica Indonesiana, 54, 232-235. https://doi.org/10.14238/pi54.4.2014.232-5

[42] Meenakshisundaram, R., Rajendiran, C., Thirumalaikolundusubramanian P. (2010) Lipid and Lipoprotein Profiles among Middle Aged Male Smokers: A Study from Southern India. Tobacco Induced Diseases, 8, 11. https://doi.org/10.1186/1617-9625-8-11

[43] Guedes, D.P., Guedes, J.E.R.P., Barbosa, D.S. and de Oliveira, J.A. (2007) Tobacco Use and Plasma Lipid-Lipoprotein Profile in Adolescents. Revista da Associação Médica Brasileira, 53, 59-63. https://doi.org/10.1590/S0104-42302007000100021

[44] Hill, J.S., Hayden, M.R., Frohlich, J. and Pritchard, P.H. (1991) Genetic and Environmental Factors Affecting the Incidence of Coronary Artery Disease in Heterozygous Familial Hypercholesterolemia. Arteriosclerosis, Thrombosis, and Vascular Biology, 11, 290-297. https://doi.org/10.1161/01.ATV.11.2.290

[45] McGill, H.C. and McMahan, C.A. (1998) Determinants of Atherosclerosis in the Young. American Journal of Cardiology, 82, 30-36.

https://doi.org/10.1016/S0002-9149(98)00720-6

[46] Czerwinski, S.A., Mahaney, M.C., Rainwater, D.L., Vandeberg, J.L., MacCluer, J.W., Stern, M.P., et al. (2004) Gene by Smoking Interaction: Evidence for Effects on Low-Density Lipoprotein Size and Plasma Levels of Triglyceride and High-Density Lipoprotein Cholesterol. Human Biology, 76, 863-876. https://doi.org/10.1353/hub.2005.0014

[47] Reilly, M., Delanty, N., Lawson, J.A. and FitzGerald, G.A. (1996) Modulation of Oxidant Stress in Vivo in Chronic Cigarette Smokers. Circulation, 94, 19-25. https://doi.org/10.1161/01.CIR.94.1.19

[48] Valkonen, M. and Kuusi, T. (1998) Passive Smoking Induces Atherogenic Changes in Low-Density Lipoprotein. Circulation, 97, 2012-2016. https://doi.org/10.1161/01.CIR.97.20.2012

[49] Niki, E. (1991) Action of Ascorbic Acid as a Scavenger of Active and Stable Oxygen Radicals. The American Journal of Clinical Nutrition, 54, 1119S-1124S. https://doi.org/10.1093/ajcn/54.6.1119s

[50] Frei, B. (1991) Ascorbic Acid Protects Lipids in Human Plasma and Low-Density Lipoprotein against Oxidative Damage. The American Journal of Clinical Nutrition, 54, 1113S-1118S.

[51] Schectman, G., Byrd, J.C. and Gruchow, H.W. (1989) The Influence of Smoking on Vitamin C Status in Adults. American Journal of Public Health, 79, 158-162. https://doi.org/10.2105/AJPH.79.2.158

[52] Celermajer, D.S., Adams, M.R., Clarkson, P., Robinson, J., McCredie, R., Donald, A., et al. (1996) Passive Smoking and Impaired Endothelium-Dependent Arterial Dilatation in Healthy Young Adults. The New England Journal of Medicine, 34, 150-155. https://doi.org/10.1056/NEJM199601183340303

[53] McMurray, H.F., Parthasarathy, S. and Steinberg, D. (1993) Oxidatively Modified 
Low Density Lipoprotein Is a Chemoattractant for Human T Lymphocytes. The Journal of Clinical Investigation, 92, 1004-1008. https://doi.org/10.1172/JCI116605

[54] Quinn, M.T., Parthasarathy, S., Fong, L.G. and Steinberg, D. (1987) Oxidatively Modified Low Density Lipoproteins: A Potential Role in Recruitment and Retention of Monocyte/Macrophages during Atherogenesis. Proceedings of the National Academy of Sciences of the United States of America, 84, 2995-2998. https://doi.org/10.1073/pnas.84.9.2995

[55] Yang, B., Li, M., Chen, B., Xu, Y. and Li, T.-D. (2012) Deterioration of Endothelial Function and Carotid Intima-Media Thickness in Tibetan Male Adolescents Exposed to Second-Hand Smoke. Journal of the Renin-Angiotensin-Aldosterone System, 13, 413-419. https://doi.org/10.1177/1470320312440901

[56] Barnoya, J. and Glantz, S.A. (2005) Cardiovascular Effects of Secondhand Smoke: Nearly as Large as Smoking. Circulation, 111, 2684-2698. https://doi.org/10.1161/CIRCULATIONAHA.104.492215

[57] Kallio, K., Jokinen, E., Raitakari, O.T., Hämäläinen, M., Siltala, M., Volanen, I., et al. (2007) Tobacco Smoke Exposure Is Associated with Attenuated Endothelial Function in 11-Year-Old Healthy Children. Circulation, 115, 3205-3212. https://doi.org/10.1161/CIRCULATIONAHA.106.674804

[58] Reriani, M.K., Lerman, L.O. and Lerman, A. (2010) Endothelial Function as a Functional Expression of Cardiovascular Risk Factors. Biomarkers in Medicine, 4, 351-360. https://doi.org/10.2217/bmm.10.61

[59] Puranik, R. and Celermajer, D.S. (2003) Smoking and Endothelial Function. Progress in Cardiovascular Diseases, 45, 443-458. https://doi.org/10.1053/pcad.2003.YPCAD13

[60] Miyazaki, H., Matsuoka, H., Cooke, J.P., Usui, M., Ueda, S., Okuda, S., et al. (1999) Endogenous Nitric Oxide Synthase Inhibitor: A Novel Marker of Atherosclerosis. Circulation, 99, 1141-1146. https://doi.org/10.1161/01.CIR.99.9.1141

[61] Benowitz, N.L. and Jacob, P. (1994) Metabolism of Nicotine to Cotinine Studied by a Dual Stable Isotope Method. Clinical Pharmacology \& Therapeutics, 56, 483-493. https://doi.org/10.1038/clpt.1994.169

[62] Chen, W., Yun, M., Fernandez, C., Li, S., Sun, D., Lai, C.-C., et al. (2015) Secondhand Smoke Exposure Is Associated with Increased Carotid Artery Intima-Media Thickness: The Bogalusa Heart Study. Atherosclerosis, 240, 374-379. https://doi.org/10.1016/j.atherosclerosis.2015.04.002

[63] Kosecik, M., Erel, O., Sevinc, E. and Selek, S. (2005) Increased Oxidative Stress in Children Exposed to Passive Smoking. International Journal of Cardiology, 100, 61-64. https://doi.org/10.1016/j.ijcard.2004.05.069

[64] Aycicek, A., Erel, O. and Kocyigit, A. (2005) Increased Oxidative Stress in Infants Exposed to Passive Smoking. European Journal of Pediatrics, 164, 775-778. https://doi.org/10.1007/s00431-005-1720-1

[65] Polidori, M.C., Mecocci, P., Stahl, W. and Sies, H. (2003) Cigarette Smoking Cessation Increases Plasma Levels of Several Antioxidant Micronutrients and Improves Resistance towards Oxidative Challenge. British Journal of Nutrition, 90, 147-150. https://doi.org/10.1079/BJN2003890

[66] Cook, D. and Strachan, D. (1998) Parental Smoking, Bronchial Reactivity and Peak Flow Variability in Children. Thorax, 53, 295-301. https://doi.org/10.1136/thx.53.4.295

[67] Kirkham, F.J., Prengler, M., Hewes, D.K. and Ganesan, V. (2000) Risk Factors for Arterial Ischemic Stroke in Children. Journal of Child Neurology, 15, 299-307. 
https://doi.org/10.1177/088307380001500506

[68] Sträter, R., Becker, S., von Eckardstein, A., Heinecke, A., Gutsche, S., Junker, R., et al. (2002) Prospective Assessment of Risk Factors for Recurrent Stroke during Childhood-A 5-Year Follow-Up Study. Lancet, 360, 1540-1545. https://doi.org/10.1016/S0140-6736(02)11520-0

[69] Nowak-Göttl, U., Sträter, R., Heinecke, A., Junker, R., Koch, H.G., Schuierer, G., et al. (1999) Lipoprotein (a) and Genetic Polymorphisms of Clotting Factor V, Prothrombin, and Methylenetetrahydrofolate Reductase are Risk Factors of Spontaneous Ischemic Stroke in Childhood. Blood, 94, 3678-3682.

[70] Haywood, S., Liesner, R., Pindora, S. and Ganesan V. (2005) Thrombophilia and First Arterial Ischaemic Stroke: A Systematic Review. Archives of Disease in Childhood, 90, 402-405. https://doi.org/10.1136/adc.2004.049163

[71] Laing, S.P., Swerdlow, A.J., Slater, S.D., Botha, J.L., Burden, A.C., Waugh, N.R., et al. (1999) The British Diabetic Association Cohort Study, II: Cause-Specific Mortality in Patients with Insulin-Treated Diabetes Mellitus. Diabetic Medicine, 16, 466-471. https://doi.org/10.1046/j.1464-5491.1999.00076.x

[72] Donahue, R.P. and Orchard, T.J. (1992) Diabetes Mellitus and Macrovascular Complications: An Epidemiological Perspective. Diabetes Care, 15, 1141-1155. https://doi.org/10.2337/diacare.15.9.1141

[73] Ebara, T., Conde, K., Kako, Y., Liu, Y., Xu, Y., Ramakrishnan, R., et al. (2000) Delayed Catabolism of ApoB-48 Lipoproteins due to Decreased Heparan Sulfate Proteoglycan Production in Diabetic Mice. Journal of Clinical Investigation, 105, 1807-1818. https://doi.org/10.1172/JCI8283

[74] Cree-Green, M., Maahs, D.M., Ferland, A., Hokanson, J.E., Wang, H., Pyle, L., et al. (2016) Lipoprotein Subfraction Cholesterol Distribution Is More Atherogenic in Insulin Resistant Adolescents with Type 1 Diabetes. Pediatric Diabetes, 17, 257-265. https://doi.org/10.1111/pedi.12277

[75] Thomas, N.E., Rowe, D.A., Murtagh, E.M., Stephens, J.W. and Williams, R. (2018) Associations between Metabolic Syndrome Components and Markers of Inflammation in Welsh School Children. European Journal of Pediatrics, 177, 409-417.

[76] Fagot-Campagna, A., Knowler, W.C. and Pettitt, D.J. (1998) Type 2 Diabetes in Pima Indian Children: Cardiovascular Risk Factors at Diagnosis and 10 Years Later. Diabetes, 47.

[77] Stout, R.W., Bierman, E.L. and Ross, R. (1975) Effect of Insulin on the Proliferation of Cultured Primate Arterial Smooth Muscle Cells. Circulation Research, 36, 319-327. https://doi.org/10.1161/01.RES.36.2.319

[78] Landsberg, L. (1992) Hyperinsulinemia: Possible Role in Obesity-Induced Hypertension. Hypertension, 19, I61. https://doi.org/10.1161/01.HYP.19.1_Suppl.I61

[79] Haller, M.J., Samyn, M., Nichols, W.W., Brusko, T., Wasserfall, C., Schwartz, R.F., et al. (2004) Radial Artery Tonometry Demonstrates Arterial Stiffness in Children with Type 1 Diabetes. Diabetes Care, 27, 2911-2917. https://doi.org/10.2337/diacare.27.12.2911

[80] Heier, M., Stensæth, K.H., Brunborg, C., Seljeflot, I., Margeirsdottir, H.D., Hanssen, K.F., et al. (2017) Increased Arterial Stiffness in Childhood Onset Diabetes: A Cardiovascular Magnetic Resonance Study. European Heart Journal-Cardiovascular Imaging, jex178. https://doi.org/10.1093/ehjci/jex178

[81] Harris, S.B., Ekoé, J.-M., Zdanowicz, Y. and Webster-Bogaert, S. (2005) Glycemic Control and Morbidity in the Canadian Primary Care Setting (Results of the Diabetes in Canada Evaluation Study). Diabetes Research and Clinical Practice, 70, 
90-97. https://doi.org/10.1016/j.diabres.2005.03.024

[82] Witztum, J.L. and Steinberg, D. (2001) The Oxidative Modification Hypothesis of Atherosclerosis: Does It Hold for Humans? Trends in Cardiovascular Medicine, 11, 93-102. https://doi.org/10.1016/S1050-1738(01)00111-6

[83] Kontush, A., Chantepie, S. and Chapman, M.J. (2003) Small, Dense HDL Particles Exert Potent Protection of Atherogenic LDL against Oxidative Stress. Arteriosclerosis, Thrombosis, and Vascular Biology, 23, 1881-1888. https://doi.org/10.1161/01.ATV.0000091338.93223.E8

[84] Wood, R.J., Volek, J.S., Liu, Y., Shachter, N.S., Contois, J.H. and Fernandez, M.L. (2006) Carbohydrate Restriction Alters Lipoprotein Metabolism by Modifying VLDL, LDL, and HDL Subfraction Distribution and Size in Overweight Men. The Journal of Nutrition, 136, 384-389. https://doi.org/10.1093/jn/136.2.384

[85] Maahs, D.M., Hokanson, J.E., Wang, H., Kinney, G.L., Snell-Bergeon, J.K., East, A., et al. (2010) Lipoprotein Subfraction Cholesterol Distribution Is Proatherogenic in Women with Type 1 Diabetes and Insulin Resistance. Diabetes, 59, 1771-1779. https://doi.org/10.2337/db09-1626

[86] Colhoun, H.M., Otvos, J.D., Rubens, M.B., Taskinen, M.R., Underwood, S.R. and Fuller, J.H. (2002) Lipoprotein Subclasses and Particle Sizes and Their Relationship with Coronary Artery Calcification in Men and Women with and without Type 1 Diabetes. Diabetes, 51, 1949-1956. https://doi.org/10.2337/diabetes.51.6.1949

[87] Maahs, D., Dabelea, D., D’Agostino, R., Andrews, J., Shah, A., Crimmins, N., et al. (2013) Glucose Control Predicts 2-Year Change in Lipid Profile in Youth with Type 1 Diabetes. Journal of Pediatrics, 162, 101-107.

[88] Heyman, E., Berthon, P., Youssef, H., Delamarche, A., Briard, D., Gamelin, F.X., et al. (2012) Metabolic Dysfunction in Late-Puberty Adolescent Girls with Type 1 Diabetes: Relationship to Physical Activity and Dietary Intakes. Diabetes \& Metabolism, 38, 337-342. https://doi.org/10.1016/j.diabet.2012.03.001

[89] Steinberger, J., Daniels, S.R., Eckel, R.H., Hayman, L., Lustig, R.H., McCrindle, B., et al. (2009) Progress and Challenges in Metabolic Syndrome in Children and Adolescents: A Scientific Statement from the American Heart Association Atherosclerosis, Hypertension, and Obesity in the Young Committee of the Council on Cardiovascular Disease in the Young, Council on Cardiovascular Nursing, and Council on Nutrition, Physical Activity, and Metabolism. Circulation, 119, 628-647. https://doi.org/10.1161/CIRCULATIONAHA.108.191394

[90] Galili, O., Versari, D., Sattler, K.J., Olson, M.L., Mannheim, D., McConnell, J.P., et al. (2007) Early Experimental Obesity Is Associated with Coronary Endothelial Dysfunction and Oxidative Stress. American Journal of Physiology-Heart and Circulatory Physiology, 292, H904-H911. https://doi.org/10.1152/ajpheart.00628.2006

[91] Túri, S., Friedman, A., Bereczki, C., Papp, F., Kovàcs, J., Karg, E., et al. (2003) Oxidative Stress in Juvenile Essential Hypertension. Journal of Hypertension, 21, 145-152. https://doi.org/10.1097/00004872-200301000-00024

[92] Sinaiko, A.R., Steinberger, J., Moran, A., Prineas, R.J., Vessby, B., Basu, S., et al. (2005) Relation of Body Mass Index and Insulin Resistance to Cardiovascular Risk Factors, Inflammatory Factors, and Oxidative Stress during Adolescence. Circulation, 111, 1985-1991. https://doi.org/10.1161/01.CIR.0000161837.23846.57

[93] Besseling, J., Kastelein, J.J.P., Defesche, J.C., Hutten, B.A. and Hovingh, G.K. (2015) Association between Familial Hypercholesterolemia and Prevalence of Type 2 Diabetes Mellitus. JAMA, 313, 1029-1036. https://doi.org/10.1001/jama.2015.1206

[94] Sattar, N., Preiss, D., Murray, H.M., Welsh, P., Buckley, B.M., de Craen, A.J., et al. 
(2010) Statins and Risk of Incident Diabetes: A Collaborative Meta-Analysis of Randomised Statin Trials. Lancet, 375, 735-742. https://doi.org/10.1016/S0140-6736(09)61965-6

[95] Preiss, D., Seshasai, S.R.K., Welsh, P., Murphy, S.A., Ho, J.E., Waters, D.D., et al. (2011) Risk of Incident Diabetes with Intensive-Dose Compared with Moderate-Dose Statin Therapy: A Meta-Analysis. JAMA, 305, 2556-2564. https://doi.org/10.1001/jama.2011.860

[96] Sattar, N. and Taskinen, M.-R. (2012) Statins Are Diabetogenic-Myth or Reality? Atherosclerosis Supplements, 13, 1-10. https://doi.org/10.1016/j.atherosclerosissup.2012.06.001

[97] Mills, E.J., Wu, P., Chong, G., Ghement, I., Singh, S., Akl, E.A., et al. (2011) Efficacy and Safety of Statin Treatment for Cardiovascular Disease: A Network Meta-Analysis of 170,255 Patients from 76 Randomized Trials. QJM: An International Journal of Medicine, 104, 109-124. https://doi.org/10.1093/qjmed/hcq165

[98] Cnop, M., Hannaert, J.C., Grupping, A.Y. and Pipeleers, D.G. (2002) Low Density Lipoprotein Can Cause Death of Islet $\beta$-Cells by Its Cellular Uptake and Oxidative Modification. Endocrinology, 143, 3449-3453.

https://doi.org/10.1210/en.2002-220273

[99] Roehrich, M.-E., Mooser, V., Lenain, V., Herz, J., Nimpf, J., Azhar, S., et al. (2003) Insulin-Secreting $\beta$-Cell Dysfunction Induced by Human Lipoproteins. Journal of Biological Chemistry, 278, 18368-18375. https://doi.org/10.1074/jbc.M300102200

[100] Rütti, S., Ehses, J.A., Sibler, R.A., Prazak, R., Rohrer, L., Georgopoulos, S., et al. (2009) Low- and High-Density Lipoproteins Modulate Function, Apoptosis, and Proliferation of Primary Human and Murine Pancreatic $\beta$-Cells. Endocrinology, 150, 4521-4530. https://doi.org/10.1210/en.2009-0252

[101] Fuentes, F., Alcala-Diaz, J.F., Watts, G.F., Alonso, R., Muñiz, O., Díaz-Díaz, J.L., et al. (2015) Statins Do Not Increase the Risk of Developing Type 2 Diabetes in Familial Hypercholesterolemia: The SAFEHEART Study. International Journal of Cardiology, 201, 79-84. https://doi.org/10.1016/j.ijcard.2015.07.107

[102] Kannel, W.B. (1996) Blood Pressure as a Cardiovascular Risk Factor: Prevention and Treatment. JAMA, 275, 1571-1576. https://doi.org/10.1001/jama.1996.03530440051036

[103] Juhola, J., Magnussen, C.G., Viikari, J.S.A., Kähönen, M., Hutri-Kähönen, N., Jula, A., et al. (2011) Tracking of Serum Lipid Levels, Blood Pressure, and Body Mass Index from Childhood to Adulthood: The Cardiovascular Risk in Young Finns Study. Journal of Pediatrics, 159, 584-590. https://doi.org/10.1016/j.jpeds.2011.03.021

[104] Jungers, P., Massy, Z.A., Nguyen Khoa, T., Fumeron, C., Labrunie, M., Lacour, B., et al. (1997) Incidence and Risk Factors of Atherosclerotic Cardiovascular Accidents in Predialysis Chronic Renal Failure Patients: A Prospective Study. Nephrology Dialysis Transplantation, 12, 2597-2602. https://doi.org/10.1093/ndt/12.12.2597

[105] Maggi, E., Bellazzi, R., Falaschi, F., Frattoni, A., Perani, G., Finardi, G., et al. (1994) Enhanced LDL Oxidation in Uremic Patients: An Additional Mechanism for Accelerated Atherosclerosis? Kidney International, 45, 876-883. https://doi.org/10.1038/ki.1994.115

[106] Dharmarajan, S.H., Bragg-Gresham, J.L., Morgenstern, H., Gillespie, B.W., Li, Y., Powe, N.R., et al. (2017) State-Level Awareness of Chronic Kidney Disease in the U.S. American Journal of Preventive Medicine, 53, 300-307. https://doi.org/10.1016/j.amepre.2017.02.015 
[107] Boyd, G.S., Koenigsberg, J., Falkner, B., Gidding, S. and Hassink, S. (2005) Effect of Obesity and High Blood Pressure on Plasma Lipid Levels in Children and Adolescents. Pediatrics, 116, 442-446. https://doi.org/10.1542/peds.2004-1877

[108] Cuspidi, C., Rescaldani, M., Sala, C. and Grassi, G. (2014) Left-Ventricular Hypertrophy and Obesity: A Systematic Review and Meta-Analysis of Echocardiographic Studies. Journal of Hypertension, 32, 16-25. https://doi.org/10.1097/HJH.0b013e328364fb58

[109] Lai, C.-C., Sun, D., Cen, R., Wang, J., Li, S., Fernandez-Alonso, C., et al. (2014) Impact of Long-Term Burden of Excessive Adiposity and Elevated Blood Pressure from Childhood on Adulthood Left Ventricular Remodeling Patterns: The Bogalusa Heart Study. Journal of the American College of Cardiology, 64, 1580-1587. https://doi.org/10.1016/j.jacc.2014.05.072

[110] Li, X., Li, S., Ulusoy, E., Chen, W., Srinivasan, S.R. and Berenson, G.S. (2004) Childhood Adiposity as a Predictor of Cardiac Mass in Adulthood: The Bogalusa Heart Study. Circulation, 110, 3488-3492. https://doi.org/10.1161/01.CIR.0000149713.48317.27

[111] Toprak, A., Wang, H., Chen, W., Paul, T., Srinivasan, S. and Berenson, G. (2008) Relation of Childhood Risk Factors to Left Ventricular Hypertrophy (Eccentric or Concentric) in Relatively Young Adulthood (from the Bogalusa Heart Study). American Journal of Cardiology, 101, 1621-1625. https://doi.org/10.1016/j.amjcard.2008.01.045

[112] Urbina, E.M., Gidding, S.S., Bao, W., Pickoff, A.S., Berdusis, K. and Berenson, G.S. (1995) Effect of Body Size, Ponderosity, and Blood Pressure on left Ventricular Growth in Children and Young Adults in the Bogalusa Heart Study. Circulation, 91, 2400-2406. https://doi.org/10.1161/01.CIR.91.9.2400

[113] Dhuper, S., Abdullah, R.A., Weichbrod, L., Mahdi, E. and Cohen, H.W. (2011) Association of Obesity and Hypertension with Left Ventricular Geometry and Function in Children and Adolescents. Obesity, 19, 128-133. https://doi.org/10.1038/oby.2010.134

[114] Mann, S., Beedie, C. and Jimenez, A. (2014) Differential Effects of Aerobic Exercise, Resistance Training and Combined Exercise Modalities on Cholesterol and the Lipid Profile: Review, Synthesis and Recommendations. Sports Medicine, 44, 211-221. https://doi.org/10.1007/s40279-013-0110-5

[115] Pälve, K.S., Pahkala, K., Magnussen, C.G., Koivistoinen, T., Juonala, M., Kähönen, M., et al. (2014) Association of Physical Activity in Childhood and Early Adulthood with Carotid Artery Elasticity 21 Years Later: The Cardiovascular Risk in Young Finns Study. Journal of the American Heart Association, 3, e000594. https://doi.org/10.1161/JAHA.113.000594

[116] Moreau, K.L., Donato, A.J., Seals, D.R., DeSouza, C.A. and Tanaka, H. (2003) Regular Exercise, Hormone Replacement Therapy and the Age-Related Decline in Carotid Arterial Compliance in Healthy Women. Cardiovascular Research, 57, 861-868. https://doi.org/10.1016/S0008-6363(02)00777-0

[117] Nualnim, N., Barnes, J.N., Tarumi, T., Renzi, C.P. and Tanaka, H. (2011) Comparison of Central Artery Elasticity in Swimmers, Runners, and the Sedentary. American Journal of Cardiology, 107, 783-787. https://doi.org/10.1016/j.amjcard.2010.10.062

[118] Gando, Y., Yamamoto, K., Murakami, H., Ohmori, Y., Kawakami, R., Sanada, K., et al. (2010) Longer Time Spent in Light Physical Activity Is Associated with Reduced Arterial Stiffness in Older Adults. Hypertension, 56, 540-546. 
https://doi.org/10.1161/HYPERTENSIONAHA.110.156331

[119] McGavock, J.M., Anderson, T.J. and Lewanczuk, R.Z. (2006) Sedentary Lifestyle and Antecedents of Cardiovascular Disease in Young Adults. American Journal of Hypertension, 19, 701-707. https://doi.org/10.1016/j.amjhyper.2006.01.013

[120] Maffeis, C., Fornari, E., Morandi, A., Piona, C., Tomasselli, F., Tommasi, M., et al. (2017) Glucose-Independent Association of Adiposity and Diet Composition with Cardiovascular Risk in Children and Adolescents with Type 1 Diabetes. Acta Diabetologica, 54, 599-605. https://doi.org/10.1007/s00592-017-0993-y

[121] National Heart, Lung and Blood Institute (2011) Expert Panel on Integrated Guidelines for Cardiovascular Health and Risk Reduction in Children and Adolescents: Summary Report. Pediatrics, 128, S213-S256. https://doi.org/10.1542/peds.2009-2107C

[122] Daniels, S.R. (2015) Pediatric Guidelines for Dyslipidemia. Journal of Clinical Lipidology, 9, S5-S10. https://doi.org/10.1016/j.jacl.2015.03.105

[123] Bertrais, S., Balkau, B., Charles, M.A., Vol, S., Calvet, C., Tichet, J., et al. (2000) Puberty-Associated Differences in Total Cholesterol and Triglyceride Levels According to Sex in French Children Aged 10-13 Years. Annals of Epidemiology, 10, 316-323. https://doi.org/10.1016/S1047-2797(00)00056-9

[124] Wagner, J. and Abdel-Rahman, S.M. (2016) Pediatric Statin Administration: Navigating a Fronteir with Limited Data. Journal of Pediatric Pharmacology and Therapeutics, 21, 380-403. https://doi.org/10.5863/1551-6776-21.5.380

[125] Avis, H.J., Kusters, D.M., Vissers, M.N., Huijgen, R., Janssen, T.H., Wiegman, A., et al. (2012) Follow-Up of Children Diagnosed with Familial Hypercholesterolemia in a National Genetic Screening Program. Journal of Pediatrics, 161, 99-103.

https://doi.org/10.1016/j.jpeds.2011.12.037

[126] Ned, R.M. and Sijbrands, E.J.G. (2011) Cascade Screening for Familial Hypercholesterolemia (FH). PLoS Currents, 3, RRN1238.

https://doi.org/10.1371/currents.RRN1238

[127] Hovingh, G.K., Davidson, M.H., Kastelein, J.J.P. and O'Connor, A.M. (2013) Diagnosis and Treatment of Familial Hypercholesterolaemia. European Heart Journal, 34, 962-971. https://doi.org/10.1093/eurheartj/eht015

[128] Civeira, F. (2004) Guidelines for the Diagnosis and Management of Heterozygous Familial Hypercholesterolemia. Atherosclerosis, 173, 55-68.

https://doi.org/10.1016/j.atherosclerosis.2003.11.010

[129] Williams, R.R., Hamilton-Craig, I., Kostner, G.M., Hegele, R.A., Hayden, M.R., Pimstone, S.N., et al. (1996) MED-PED: An Integrated Genetic Strategy for Preventing Early Deaths. In: Berg, K., Boulyjenkov, V. and Christen, Y., Eds., Genetic Approaches to Noncommunicable Diseases, Springer, Berlin, Heidelberg, 35-45. https://doi.org/10.1007/978-3-642-61028-8_5

[130] Austin, M.A., Hutter, C.M., Zimmern, R.L. and Humphries, S.E. (2004) Genetic Causes of Monogenic Heterozygous Familial Hypercholesterolemia: A HuGE Prevalence Review. American Journal of Epidemiology, 160, 407-420. https://doi.org/10.1093/aje/kwh236

[131] Scientific Steering Committee on Behalf of the Simon Broome Register Group. (1991) Risk of Fatal Coronary Heart Disease in Familial Hypercholesterolaemia. BMJ, 303, 893-896.

[132] Humphries, S.E., Whittall, R.A., Hubbart, C.S., Maplebeck, S., Cooper, J.A., Soutar, A.K., et al. (2006) Genetic Causes of Familial Hypercholesterolaemia in Patients in the UK: Relation to Plasma Lipid Levels and Coronary Heart Disease Risk. Journal 
of Medical Genetics, 43, 943-949. https://doi.org/10.1136/jmg.2006.038356

[133] McCrindle, B.W., Urbina, E.M., Dennison, B.A., Jacobson, M.S., Steinberger, J., Rocchini, A.P., et al. (2007) Drug Therapy of High-Risk Lipid Abnormalities in Children and Adolescents: A Scientific Statement from the American Heart Association Atherosclerosis, Hypertension, and Obesity in Youth Committee, Council of Cardiovascular Disease in the Young, with the Council on Cardiovascular Nursing. Circulation, 115, 1948-1967. https://doi.org/10.1161/CIRCULATIONAHA.107.181946

[134] de Jongh, S., Lilien, M.R., op't Roodt, J., Stroes, E.S.G., Bakker, H.D. and Kastelein, J.J.P. (2002) Early Statin Therapy Restores Endothelial Function in Children with Familial Hypercholesterolemia. Journal of the American College of Cardiology, 40, 2117-2121. https://doi.org/10.1016/S0735-1097(02)02593-7

[135] Penny, W.F., Ben-Yehuda, O., Kuroe, K., Long, J., Bond, A., Bhargava, V., et al. (2001) Improvement of Coronary Artery Endothelial Dysfunction with Lipid-Lowering Therapy: Heterogeneity of Segmental Response and Correlation with Plasma-Oxidized Low Density Lipoprotein. Journal of the American College of Cardiology, 37, 766-774. https://doi.org/10.1016/S0735-1097(00)01180-3

[136] Masumoto, A., Hirooka, Y., Hironaga, K., Eshima, K., Setoguchi, S., Egashira, K, et al. (2001) Effect of Pravastatin on Endothelial Function in Patients with Coronary Artery Disease (Cholesterol-Independent Effect of Pravastatin). American Journal of Cardiology, 88, 1291-1294. https://doi.org/10.1016/S0002-9149(01)02090-2

[137] Betteridge, D., Broome, K., Durrington, P., Hawkins, M., Humphries, S., Mann, J., et al. (1999) Mortality in Treated Heterozygous Familial Hypercholesterolaemia: Implications for Clinical Management. Atherosclerosis, 142, 105-112. https://doi.org/10.1016/S0021-9150(98)00200-7

[138] Braamskamp, M.J.A.M., Langslet, G., McCrindle, B.W., Cassiman, D.M., Francis, G.A., Gagne, C., et al. (2017) Effect of Rosuvastatin on Carotid Intima-Media Thickness in Children with Heterozygous Familial Hypercholesterolemia: The CHARON Study. Circulation, 136, 359-366.

[139] Rodenburg, J., Vissers, M.N., Wiegman, A., van Trotsenburg, A.S.P., van der Graaf, A., de Groot, E., et al. (2007) Statin Treatment in Children with Familial Hypercholesterolemia: The Younger, the Better. Circulation, 116, 664-668. https://doi.org/10.1161/CIRCULATIONAHA.106.671016

[140] Bradford, R.H., Shear, C.L., Chremos, A.N., Dujovne, C., Downton, M., Franklin, F.A., et al. (1991) Expanded Clinical Evaluation of Lovastatin (EXCEL) Study Results. I. Efficacy in Modifying Plasma Lipoproteins and Adverse Event Profile in 8245 Patients with Moderate Hypercholesterolemia. Archives of Internal Medicine, 151, 43-49. https://doi.org/10.1161/CIRCULATIONAHA.106.671016

[141] Knopp, R.H. (1999) Drug Treatment of Lipid Disorders. New England Journal of Medicine, 341, 498-511. https://doi.org/10.1056/NEJM199908123410707

[142] O’Gorman, C.S., Higgins, M.F. and O’Neill, M.B. (2009) Systematic Review and Metaanalysis of Statins for Heterozygous Familial Hypercholesterolemia in Children: Evaluation of Cholesterol Changes and Side Effects. Pediatric Cardiology, 30, 482-489. https://doi.org/10.1007/s00246-008-9364-3

[143] Avis, H.J., Vissers, M.N., Stein, E.A., Wijburg, F.A., Trip, M.D., Kastelein, J.J.P., et al. (2007) A Systematic Review and Meta-Analysis of Statin Therapy in Children with Familial Hypercholesterolemia. Arteriosclerosis, Thrombosis, and Vascular Biology, 27, 1803-1810. https://doi.org/10.1161/ATVBAHA.107.145151

[144] Wiegman, A., Hutten, B.A., de Groot, E., Rodenburg, J., Bakker, H.D., Büller, H.R., 
et al. (2004) Efficacy and Safety of Statin Therapy in Children with Familial Hypercholesterolemia: A Randomized Controlled Trial. JAMA, 292, 331-337.

https://doi.org/10.1001/jama.292.3.331

[145] Stein, E.A., Marais, A.D., Szamosi, T., Raal, F.J., Schurr, D., Urbina, E.M., et al. (2010) Colesevelam Hydrochloride: Efficacy and Safety in Pediatric Subjects with Heterozygous Familial Hypercholesterolemia. Journal of Pediatrics, 156 231-236. https://doi.org/10.1016/j.jpeds.2009.08.037

[146] van der Graaf, A., Cuffie-Jackson, C., Vissers, M.N,. Trip, M.D., Gagné, C., Shi, G., et al. (2008) Efficacy and Safety of Coadministration of Ezetimibe and Simvastatin in Adolescents with Heterozygous Familial Hypercholesterolemia. Journal of the American College of Cardiology, 52, 1421-1429.

https://doi.org/10.1016/j.jacc.2008.09.002 